\title{
1 Monitoring of Subsidence with UAVSAR on Sherman Island in California's \\ Sacramento-San Joaquin Delta
}

3

4

5

6

7

8

9

10

3

\author{
Priyanka Sharma
}

Jet Propulsion Laboratory, California Institute of Technology, 4800 Oak Grove Drive, Pasadena, CA 91109

Priyanka.Sharma@jpl.nasa.gov

\author{
Cathleen E. Jones \\ Jet Propulsion Laboratory, California Institute of Technology, \\ 4800 Oak Grove Drive, Pasadena, CA 91109 \\ Cathleen.E.Jones@jpl.nasa.gov
}

Joel Dudas

California Department of Water Resources

1416 9th St, Sacramento, CA 95814

Joel.Dudas@water.ca.gov

Gerald W. Bawden

NASA Headquarters

300 E St SW, Washington, DC 20546

Gerald.W.Bawden@nasa.gov 
HydroFocus, Inc.

30

31

32

33 Corresponding author: Priyanka Sharma

34 Jet Propulsion Laboratory, 4800 Oak Grove Drive, M/S T1721-220, Pasadena, CA 91109

$35 \quad$ Priyanka.Sharma@jpl.nasa.gov

36 
ABSTRACT

Sherman Island, the westernmost island in the Sacramento-San Joaquin Delta in California, plays a crucial role in maintaining the water flux between saline ocean water from the San Francisco Bay to its west and the rest of the Delta to its east. Land elevation below mean sea level and continuous subsidence over the past century has made this island a high priority area for

42 investigations of subsidence and restoration in the Delta. This study reports the results of successful application of Interferometric Synthetic Aperture Radar (InSAR) data and technique to measure subsidence in the Delta, which is a coherence-challenged non-urban area. We carried out a time-series interferometric analysis of Uninhabited Aerial Vehicle Synthetic Aperture Radar (UAVSAR) L-band $(23.8 \mathrm{~cm}$ ) data, collected from July 2009-August 2014, to assess both 47 the spatial and temporal variation of subsidence on Sherman Island. We report both large-scale (island-wide) subsidence trends and small-scale (levee/farm scale) subsidence features in Sherman Island. Assuming the subsidence is linear during the five years of UAVSAR data acquisition, subsidence rates across the island range from $0-5 \mathrm{~cm} / \mathrm{yr}$, with an average of $1.3 \pm 0.2$ $\mathrm{cm} / \mathrm{yr}$. We estimate our systematic uncertainty to be $0.3 \mathrm{~cm} / \mathrm{yr}$. Overall, the central region in the island has subsided at a faster rate than the rest of the island. We find our results to be consistent with previous measurements of subsidence rates at electric transmission line towers scattered reliable water supply for the state of California and for protecting the Delta ecosystem.

Keywords: Deltas; subsidence; synthetic aperture radar; interferometry; InSAR; land use; 60 UAVSAR 


\section{Introduction}

62 The Sacramento-San Joaquin Delta (from here on referred to as the 'Delta') is located east of San

63 Francisco Bay, at the confluence of two of the largest rivers in the state of California:

64 Sacramento River which joins the Delta from the north and San Joaquin River which joins from

65 the south. The Delta itself occupies $\sim 39 \mathrm{~km}$ east to west and $\sim 77 \mathrm{~km}$ north to south (Figure 1)

66 (Lund, 2010). It is bordered by the cities of Sacramento on the northeast, Antioch on the west,

67 Tracy on the south-west and Manteca (near Stockton) on the southeast. The tidal marshland and

68 reclaimed land that make up the Delta are distributed among $\sim 70$ major islands and tracts

69 surrounded by about $1700 \mathrm{~km}$ of levees or embankments. The Delta plays a critical hydrological

70 role as the main freshwater supply for California and collects runoff from almost $40 \%$ of the

71 state's land area. It is a hub of various state, federal and local water systems and provides water

72 to about two-thirds of California's residents (Burton and Cutter, 2008; Suddeth et al., 2010;

73 Delta Science Plan, 2013). Moreover, it is also a complex estuary ecosystem and a biodiversity

74 hotspot that provides home to nearly 750 animal and plant species, some of which are threatened

75 or endangered (United States Environmental Protection Agency [USEPA], 2011).

76

77 


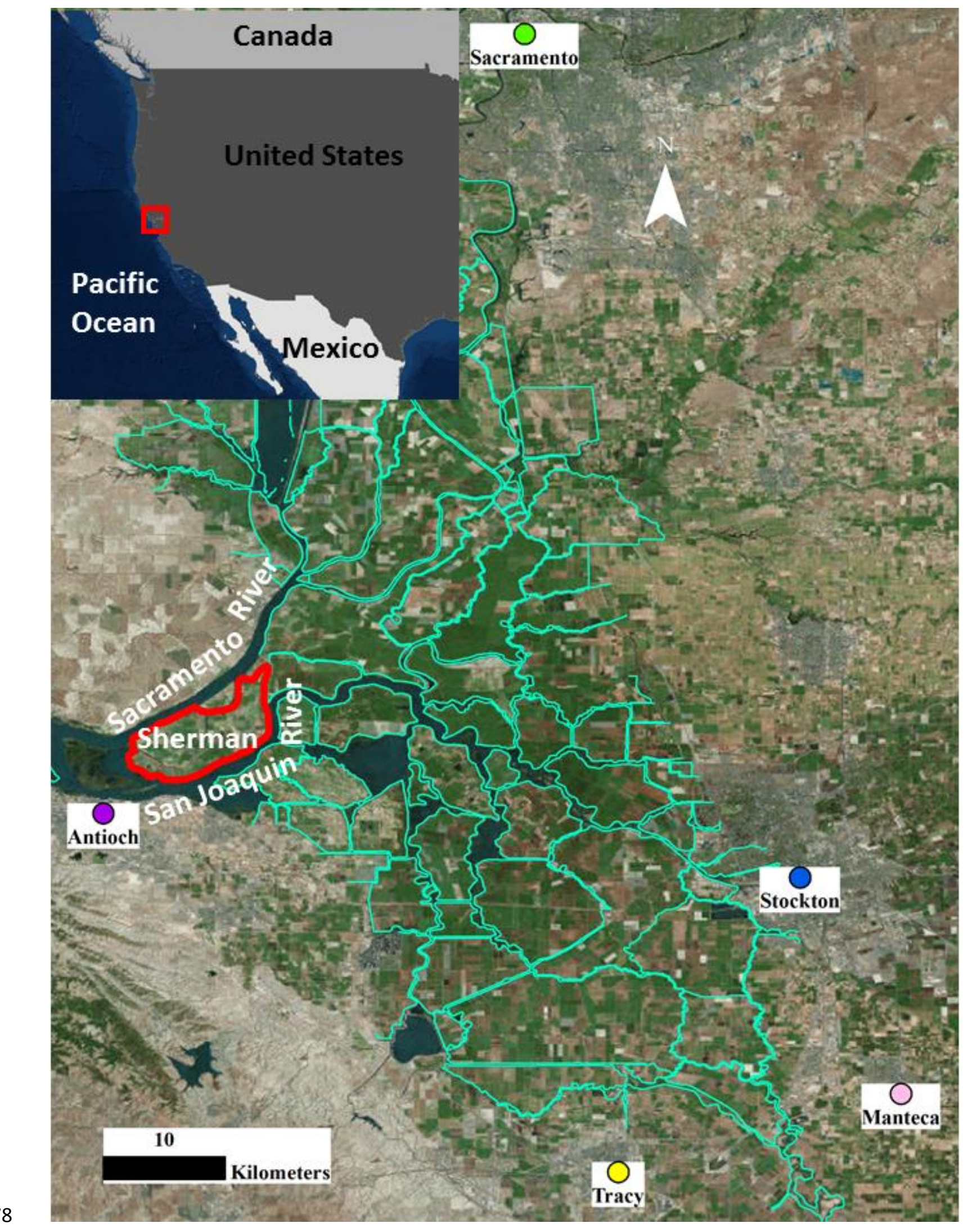


79 Figure 1. The Sacramento and San Joaquin Rivers join east of the San Francisco Bay in northern 80 California, forming the Delta. The westernmost island in the Delta, Sherman Island, is the focus 81 of this study (outlined in red). Cities forming the boundaries of the Delta are cited in the text and 82 their locations are depicted in this figure.

83

In the late 1800s and early 1900s, the tidal marshlands that constituted the Delta were 85 reclaimed and converted into farmland (Mount and Twiss, 2005). 'Reclamation' refers to the 86 drainage of existing tidal marshlands and construction of levees/embankments, channel networks 87 and drainage ditches to assist in making the region suitable for agriculture. The conversion of 88 tidal marshlands into farmland initiated the process of subsidence in the Delta. As a result of this 89 ongoing subsidence over the past century, current mean island elevations throughout the Delta 90 are below mean sea level, with some islands being as low as eight meters below sea level (Figure 91 2) (Mount and Twiss, 2005; Deverel and Rojstaczer, 1996; California Department of Water 92 Resources [CA DWR], 2007b). 


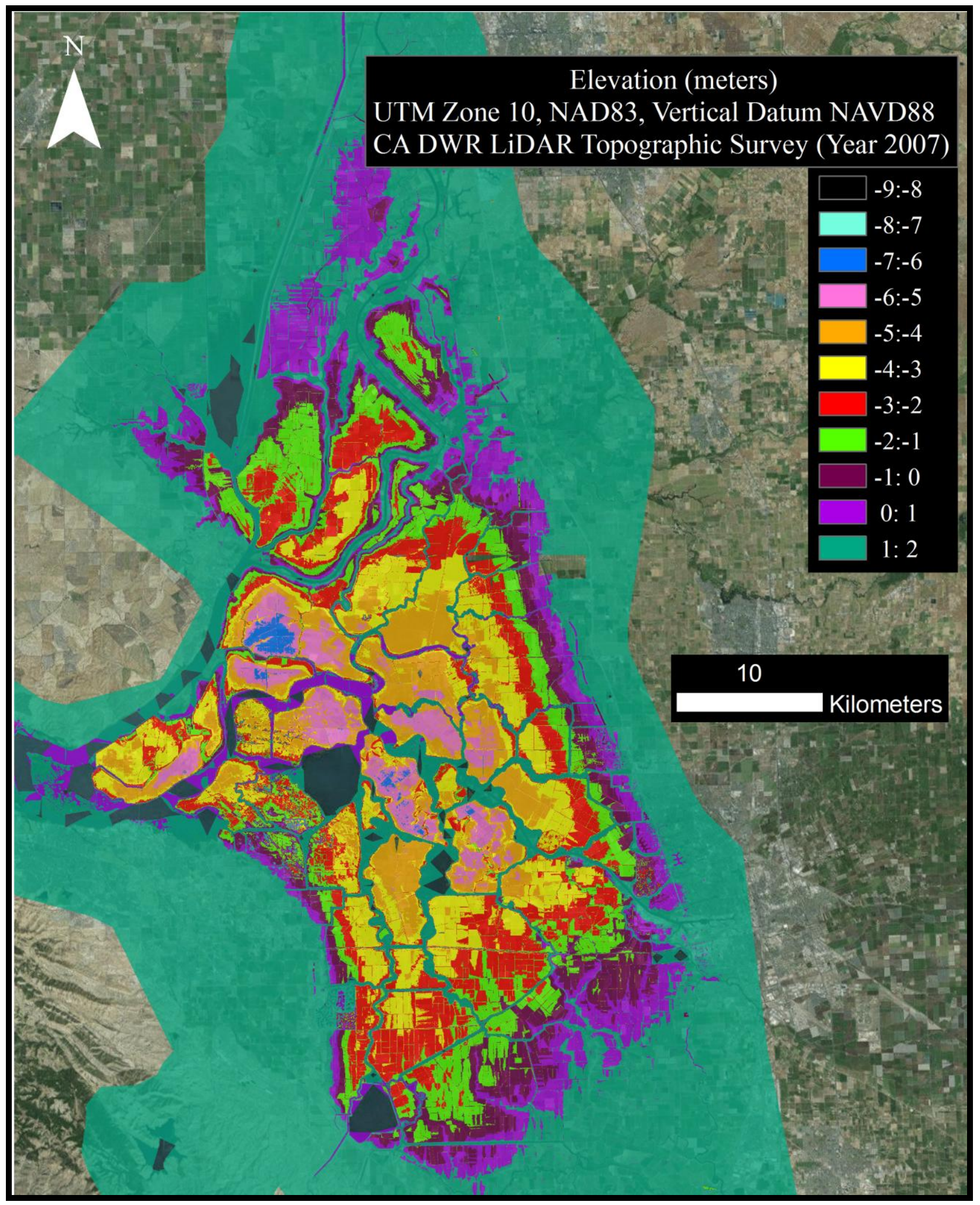

94 Figure 2. Land elevation across the Delta derived from LiDAR topographic survey conducted by

95 the California Department of Water Resources (CA DWR) in 2007-08. 
The factors causing subsidence of the Delta land surface have changed over the years. In

the early 1900s, controlled firing/burning of the surface soil was a common practice in the 99 preparation of potato fields and led to lowering of surface levels (Cosby, 1941). Later, this factor was superseded by conversion of larger tracts of land into farms, accompanied by drainage of the 101 organic-rich soils in order to lower water tables for growing crops. These drained organic soils 102 2010). Oxidation refers to the microbial oxidation of organic matter in the soil that constitutes the Delta. The rate of oxidation depends on the content of organic matter in the soil. Other 106 factors that can also contribute to subsidence include shrinkage, anaerobic decomposition, wind 107 erosion, resource withdrawal, dissolution of soil organic matter and direct harvest of soils. 108 Organic matter content and farming practices/water resources management directly contribute to 109 the variation in subsidence throughout the Delta.

Sherman Island is the westernmost island in the Sacramento-San Joaquin Delta and its 112 geographic location makes it critical for controlling the flux of seawater into the Delta (Figure 1) 113 (Fisher et al., 2011). This island was one of the first in the Delta to be reclaimed during the 114 period 1868-1879 (URS, 2009). This island is primarily used as pasture area, although 115 agricultural farming, primarily of corn, grains, and alfalfa, is also carried out in the central and 116 northeastern parts of the island (Figure 3C) (CA DWR, 2007a; National Resources Conservation 117 Service Soils [NRCSS], 1985). Land surface elevations measured with LiDAR across Sherman 118 island vary from $1 \mathrm{~m}$ to $-5 \mathrm{~m}$ relative to the sea level (levee elevations are higher than the field 
119 elevations listed here) (CA DWR, 2007b) (Figure 3A). This island has been identified as a high 120 priority island in the Delta due to its geographic location, which directly influences Delta water 121 salinity and quality. Any possible damage to this island's levees can lead to serious economic 122 consequences by potentially impacting Delta exports. The island's susceptibility to seismically123 induced liquefaction and levee collapse also make it an important region for studies of 124 subsidence (Mount and Twiss, 2005; Torres et al., 2000). Levee breaches have led to inundation 125 of portions of Sherman Island five times since 1900, with the most recent levee breach occurring 126 in 1969 (URS, 2009). The expected annual probability of flooding in Sherman Island has been 127 estimated as $>7 \%$ annually (or $>84 \%$ probability of failure over a 25 -year period), from the 128 combined risk of earthquakes, high water and dry-weather levee failures, and is amongst the 129 highest reported for all the islands in the Delta (CA DWR, 2009; Bates \& Lund, 2013). 130 Therefore, there is an immediate need for accurate monitoring of subsidence rates in Sherman 131 Island, which is essential for project planning, subsidence management and mitigation, flood 132 disaster response, and levee failure impact assessment (Service, 2007; Burton and Cutter, 2008). 


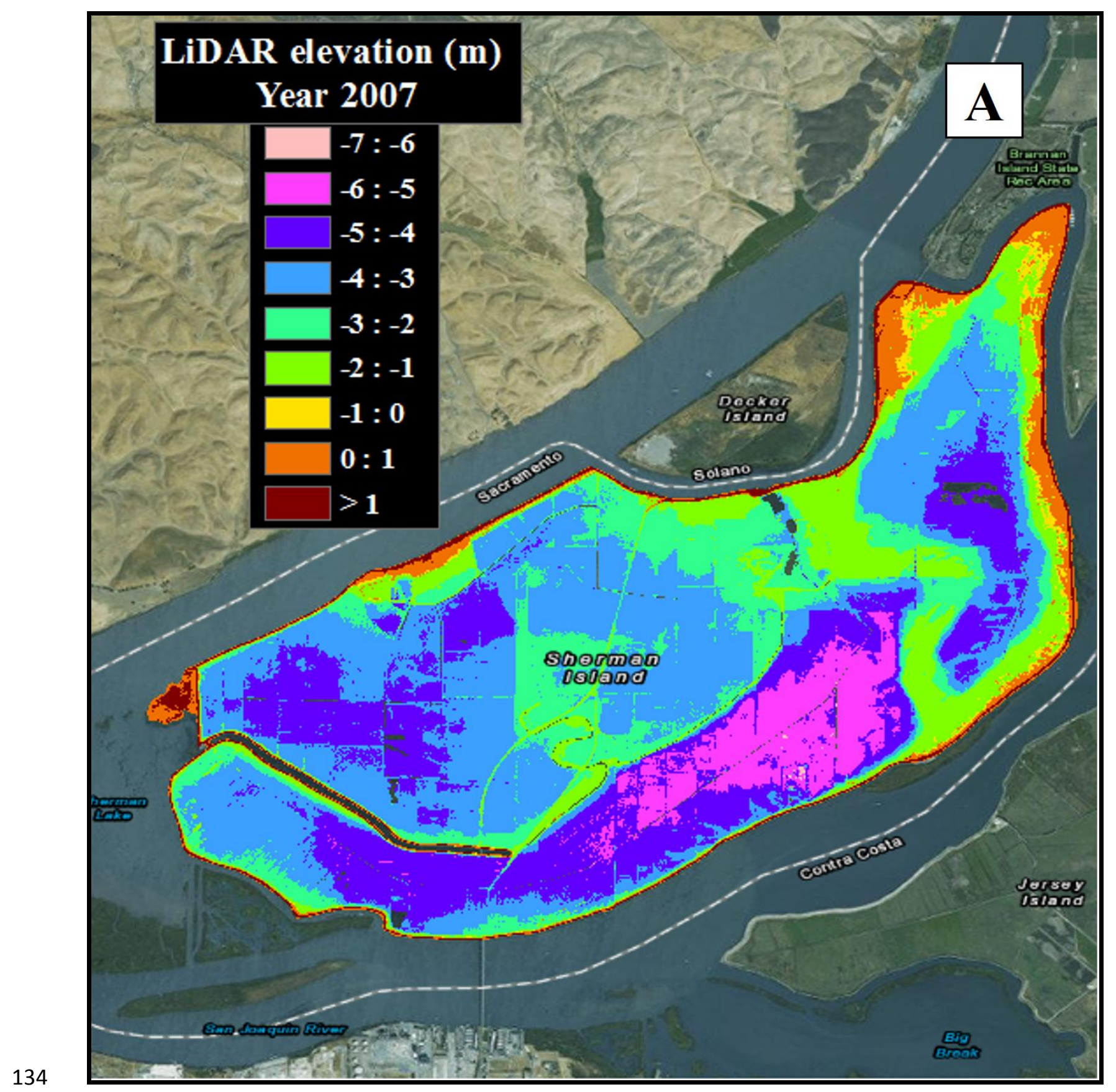




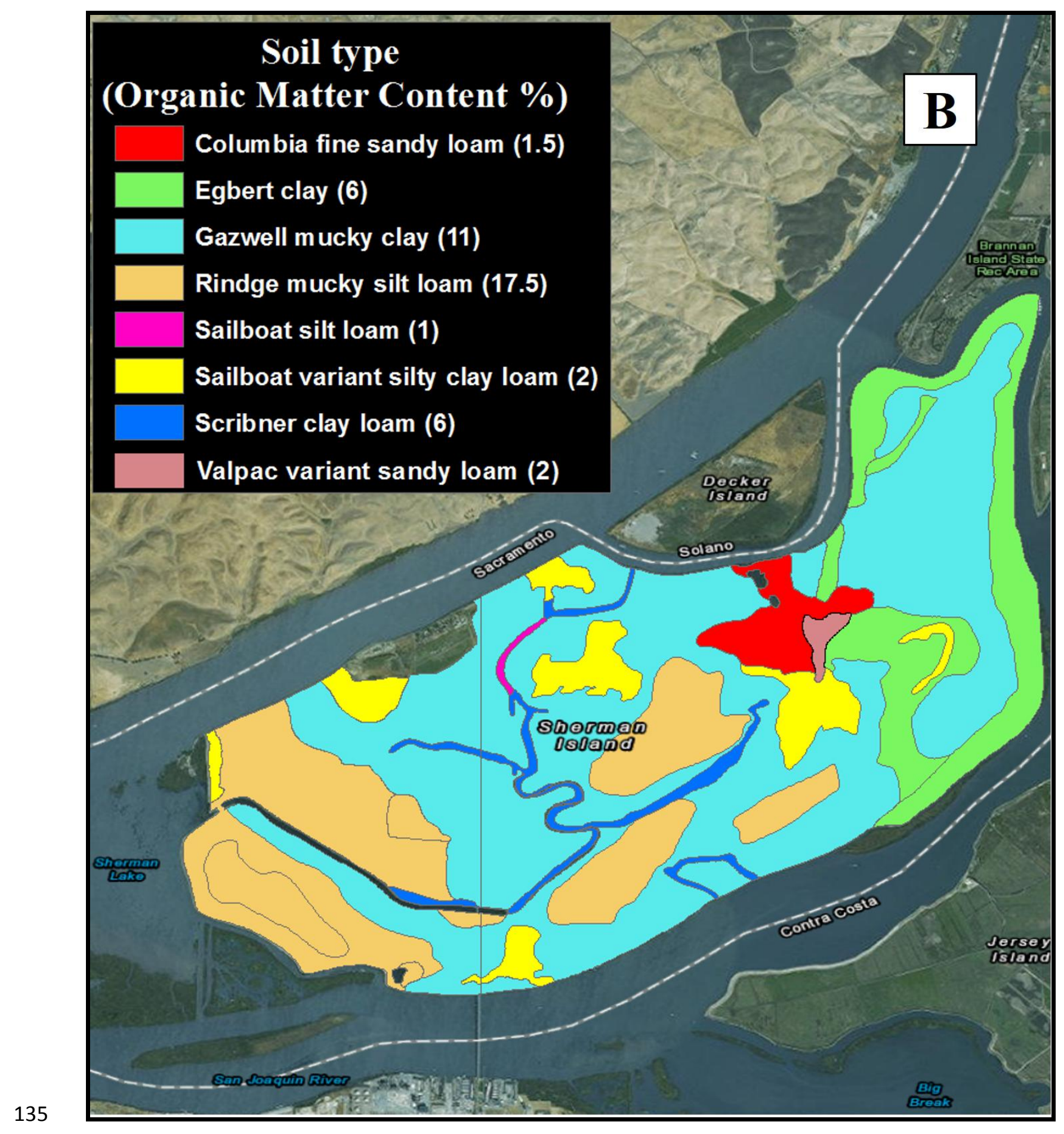




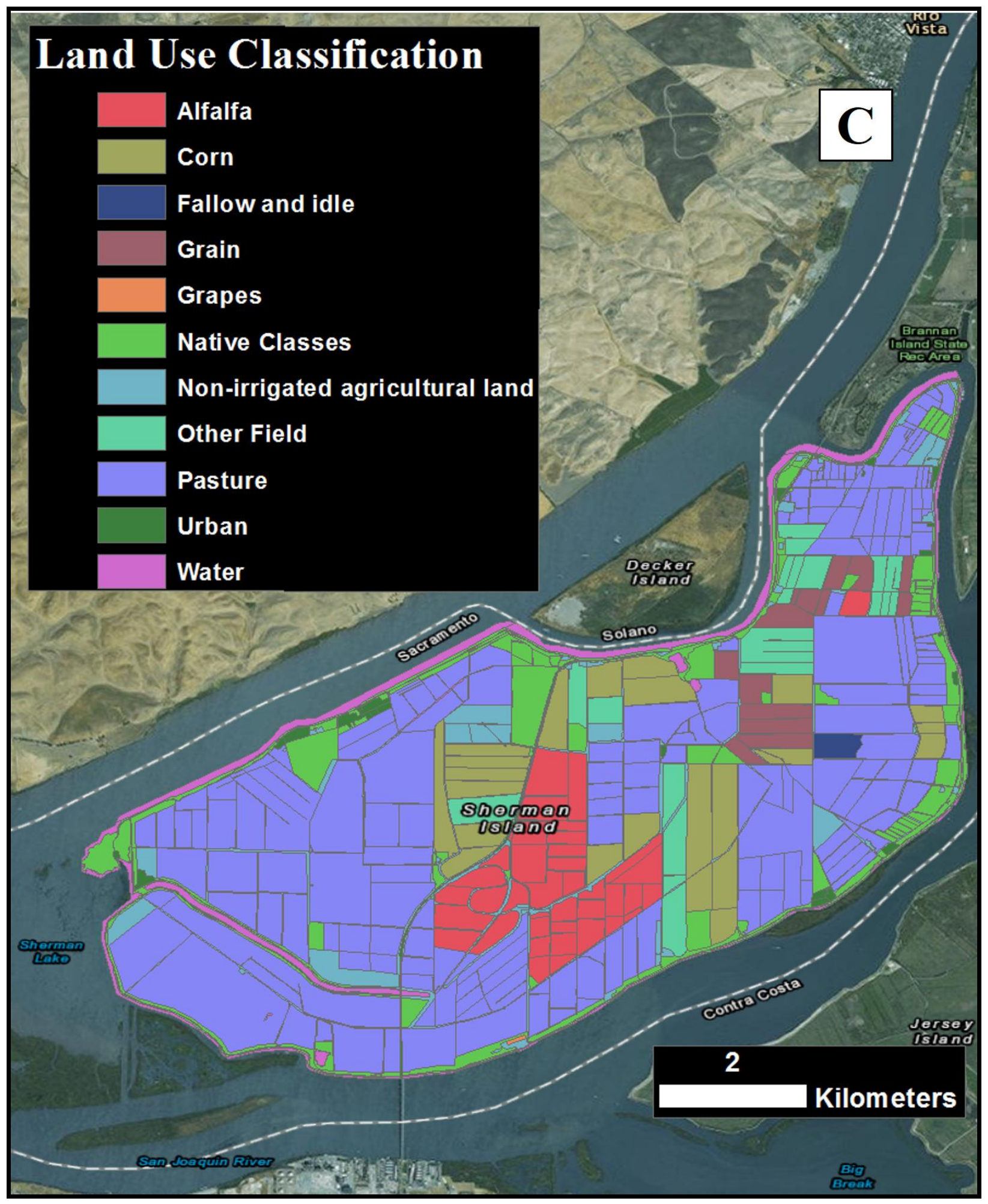

137 Figure 3. [A] LiDAR elevations across Sherman Island from the topographic survey conducted 138 by CA DWR in 2007; UTM Zone 10, NAD 83, vertical datum NAVD88 (CA DWR, 2007b), [B] 
139 Soil type classification (NRCSS, 1985) and [C] land use classification (CA DWR, 2007a) across

140 Sherman Island. It is important to point out that land use classification varies from year to year

141 and thus this survey from 2007 might not accurately depict the current land use status in the

142 island. Similarly, the soil type map is only intended to provide an island-wide distribution of

143 common soil types and should be used with caution for understanding the effect of soil organic

144 matter content on subsidence.

145

Historically, moderate subsidence rates $(1-3 \mathrm{~cm} / \mathrm{yr})$ have been recorded in this island

147 compared to the other islands in the Delta (Deverel and Leighton, 2010). Past studies of

148 subsidence in the Delta have focused on measurement of subsidence from field transect surveys

149 (Broadbent, 1960; Prokopovich, 1985; Weir, 1950); ground-based instruments like

150 extensometers (Deverel and Rojstaczer, 1996; Rojstaczer and Deverel, 1993); LiDAR surveys

151 (CA DWR, 2007b; Glennie et al., 2013); soil loss measured against electrical transmission

152 towers (Rojstaczer and Deverel, 1995); or some combination of these methods (Deverel and

153 Leighton, 2010; Rojstaczer et al., 1991). However, all of these methods have focused on

154 individual measurements made at a particular time and/or at disparate locations.

Given the variation of soil organic content, water table depth, farming, and water

157 management practices on Sherman Island, all factors affecting subsidence, it is important to

158 monitor elevation changes at high spatial resolution and with sufficient temporal duration and

159 resolution to distinguish long term subsidence trends from seasonal or episodic variation. This

160 study reports regularly acquired, spatially comprehensive measurements of subsidence across the

161 entire Sherman Island and has sufficient duration of measurements to extract linear subsidence 
162 163

rates with sub-centimeter accuracy over much of the area. The results outlined in this manuscript allow us to investigate large-scale (few kilometers; across the extent of the island) and smallscale (20-30 meters; at the scale of the levees) spatial and temporal trends of subsidence on the island. Although studies in the past have attempted to use satellite C-band (ERS-1 and ERS-2) radar data for investigating Delta subsidence, rapid decorrelation in the non-urban landscape of the Delta proved to be a limiting factor in comprehensively characterizing subsidence within the Delta's interior (Cohen et al., 1998; Brooks et al., 2012a). The relatively longer L-band (23.8 $\mathrm{cm}$ ) wavelength of the Uninhabited Aerial Vehicle Synthetic Aperture Radar (UAVSAR) imagery used in this study, combined with regular acquisitions, high spatial resolution and data processing techniques developed for low coherence regions, have allowed for the application of radar interferometry to monitor subsidence in a coherence-challenged area like the Delta.

\section{Instruments and datasets}

Data acquired by NASA JPL's Uninhabited Aerial Vehicle Synthetic Aperture Radar (UAVSAR) were utilized for this study. UAVSAR is a pod-based radar system instrumented with a quad-polarization, L-band $(23.8 \mathrm{~cm})$ synthetic aperture radar $(\mathrm{SAR})$ with a bandwidth of $80 \mathrm{MHz}$, which is flown on a NASA G-III aircraft (Hensley et al., 2008; 2009). The G-III aircraft that carries the UAVSAR flies at an altitude of $12.5 \mathrm{~km}$. Figure 4 shows the UAVSAR coverage of Sherman Island by two lines (UAVSAR line IDs SDelta_15502 and SDelta_23518), which image the island from near perpendicular directions (flight track heading is $155^{\circ}$ for line 15502 and $235^{\circ}$ for line 23518). The incidence angle for the two lines varies from $19.5^{\circ}$ in the near-range to $65.4^{\circ}$ in the far-range (for the cropped sections of the lines used for this study, the incidence angle range is $39.8^{\circ}-60.9^{\circ}$ for 15502 and $45.9^{\circ}-58.6^{\circ}$ for 23518 ). The UAVSAR has 
185 been flown over Sherman Island regularly since July 2009, yielding 47 and 50 acquisitions for 186 line 15502 and 23518, respectively, as of August 2014. The time between sequential acquisitions 187 ranges from 26 to 105 days. Table 1 lists all the UAVSAR data acquisitions utilized for this 188 study. The single-look complex data (SLC) have a pixel spacing of $0.6 \mathrm{~m}$ x $1.6 \mathrm{~m}$. (Hensley et 189 al., 2009). For this study, we have used $\mathrm{HH}$ polarization interferometric products from the 190 UAVSAR that are multi-looked by a factor of 3 (12) in the slant-range (along-track) direction, 191 which reduces the speckle noise in the images while maintaining a sufficiently high resolution to 192 well resolve the levees. The UAVSAR is the ideal instrument for conducting this analysis 193 because it has fine spatial resolution (7 m multi-look), sufficiently wide imaging swath $(22 \mathrm{~km})$, 194 and the longer wavelength (L-band, $23.8 \mathrm{~cm}$ ) required to maintain phase coherence between 195 repeat collections in the Delta (Jones et al., 2011; 2012; 2016).

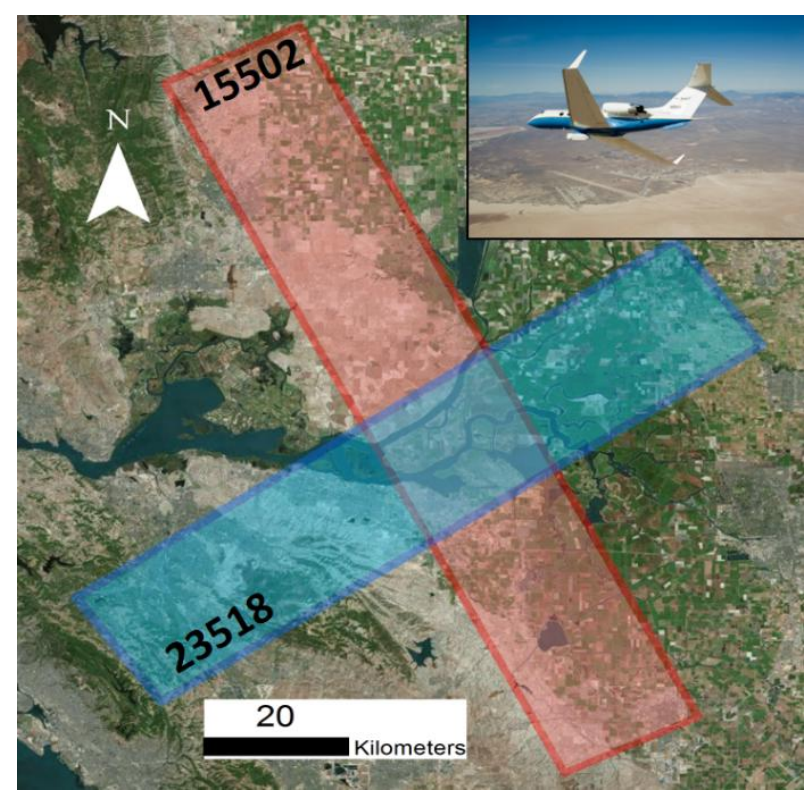

198 Figure 4. Two UAVSAR lines cover the Sherman Island in the Delta from different look 199 directions. The inset shows the NASA Gulfstream G-III aircraft that carries the UAVSAR. 
201 Table 1. Inventory of UAVSAR acquisitions used in this study.

\begin{tabular}{|c|c|c|c|}
\hline Line ID & Flight ID & $\begin{array}{c}\text { Date of } \\
\text { acquisition } \\
(\text { yyyy-mm-dd })\end{array}$ & Temporal Baseline (Days) \\
\hline $15502 / 23518$ & 09048 & 2009-07-18 & - \\
\hline $15502 / 23518$ & 09068 & 2009-09-08 & 53 \\
\hline $15502 / 23518$ & 09080 & 2009-10-03 & 26 \\
\hline $15502 / 23518$ & 09086 & 2009-11-02 & 31 \\
\hline $15502 / 23518$ & 09093 & $2009-12-03$ & 32 \\
\hline $15502 / 23518$ & 10007 & 2010-01-14 & 43 \\
\hline $15502 / 23518$ & 10025 & 2010-03-04 & 50 \\
\hline $15502 / 23518$ & 10026 & 2010-04-09 & 37 \\
\hline $15502 / 23518$ & 10036 & $2010-05-10$ & 32 \\
\hline $15502 / 23518$ & 10051 & 2010-06-17 & 39 \\
\hline $15502 / 23518$ & $10059(1)$ & $2010-07-12$ & \multirow{3}{*}{26} \\
\hline $15502 / 23518$ & $10059(2)$ & $2010-07-12$ & \\
\hline $15502 / 23518$ & 10060 & $2010-07-12$ & \\
\hline $15502 / 23518$ & 10068 & $2010-08-10$ & 30 \\
\hline $15502 / 23518$ & 10070 & 2010-09-25 & 47 \\
\hline $15502 / 23518$ & 10075 & $2010-10-25$ & 31 \\
\hline $15502 / 23518$ & 10083 & 2010-12-01 & 38 \\
\hline $15502 / 23518$ & 11003 & 2011-01-10 & 41 \\
\hline $15502 / 23518$ & 11006 & 2011-03-30 & 80 \\
\hline $15502 / 23518$ & 11027 & 2011-05-12 & 44 \\
\hline $15502 / 23518$ & $11036(1)$ & 2011-06-16 & 36 \\
\hline 23518 & $11036(2)$ & 2011-06-16 & 36 \\
\hline $15502 / 23518$ & 11051 & $2011-07-20$ & 35 \\
\hline $15502 / 23518$ & $11061(1)$ & $2011-08-29$ & 41 \\
\hline 23518 & $11061(2)$ & 2011-08-29 & 41 \\
\hline 23518 & 11062 & $2011-08-29$ & 41 \\
\hline $15502 / 23518$ & 11065 & 2011-10-03 & 36 \\
\hline $15502 / 23518$ & 11070 & 2011-11-02 & 31 \\
\hline $15502 / 23518$ & 11079 & 2011-12-07 & 36 \\
\hline $15502 / 23518$ & 12001 & 2012-01-05 & 30 \\
\hline $15502 / 23518$ & 12011 & $2012-02-13$ & 40 \\
\hline $15502 / 23518$ & 12012 & $2012-03-22$ & 39 \\
\hline $15502 / 23518$ & 12020 & 2012-04-24 & 34 \\
\hline $15502 / 23518$ & 12031 & $2012-05-30$ & 37 \\
\hline $15502 / 23518$ & 12063 & 2012-07-18 & 50 \\
\hline $15502 / 23518$ & 12070 & 2012-08-16 & 30 \\
\hline $15502 / 23518$ & 12082 & 2012-09-24 & 40 \\
\hline $15502 / 23518$ & 13002 & 2013-01-03 & 102 \\
\hline $15502 / 23518$ & 13014 & 2013-01-29 & 27 \\
\hline $15502 / 23518$ & 13069 & 2013-04-23 & 85 \\
\hline
\end{tabular}




\begin{tabular}{|c|c|c|c|}
\hline $15502 / 23518$ & 13100 & $2013-05-29$ & 37 \\
\hline $15502 / 23518$ & 13129 & $2013-07-19$ & 52 \\
\hline 15502 & 13155 & $2013-10-24$ & 98 \\
\hline 23518 & 13165 & $2013-10-31$ & 105 \\
\hline $15502 / 23518$ & 13185 & $2013-11-25$ & $33(15502) / 26(23518)$ \\
\hline $15502 / 23518$ & 14005 & $2014-01-17$ & 54 \\
\hline $15502 / 23518$ & 14019 & $2014-02-12$ & 27 \\
\hline $15502 / 23518$ & 14033 & $2014-04-02$ & 50 \\
\hline $15502 / 23518$ & 14062 & $2014-05-15$ & 44 \\
\hline $15502 / 23518$ & 14086 & $2014-06-16$ & 33 \\
\hline $15502 / 23518$ & 14112 & $2014-08-14$ & 60 \\
\hline
\end{tabular}

202

\section{Methodology}

The technique of InSAR is based on coherent processing of radar signals collected over

205 the same scene at two different times to derive surface deformation from the change in the 206 relative phase of the two returns (Figure 5) (Balmer and Hartl, 1998; Rosen et al., 2000; 207 European Space Agency, 2007; Richards, 2007). In this way, deformation along the line-of-sight 208 direction on the scale of a fraction of the radar wavelength can be resolved as long as the phase 209 coherence between the signals is maintained (Zebker and Goldstein, 1986; Gabriel et al., 1989). 210 As part of the InSAR data processing, interferograms showing the difference in interferometric 211 phase between two acquisitions over the same area are generated. Another important parameter 212 calculated during InSAR processing is the interferometric coherence, which is a measure of 213 correlation between different acquisitions. 


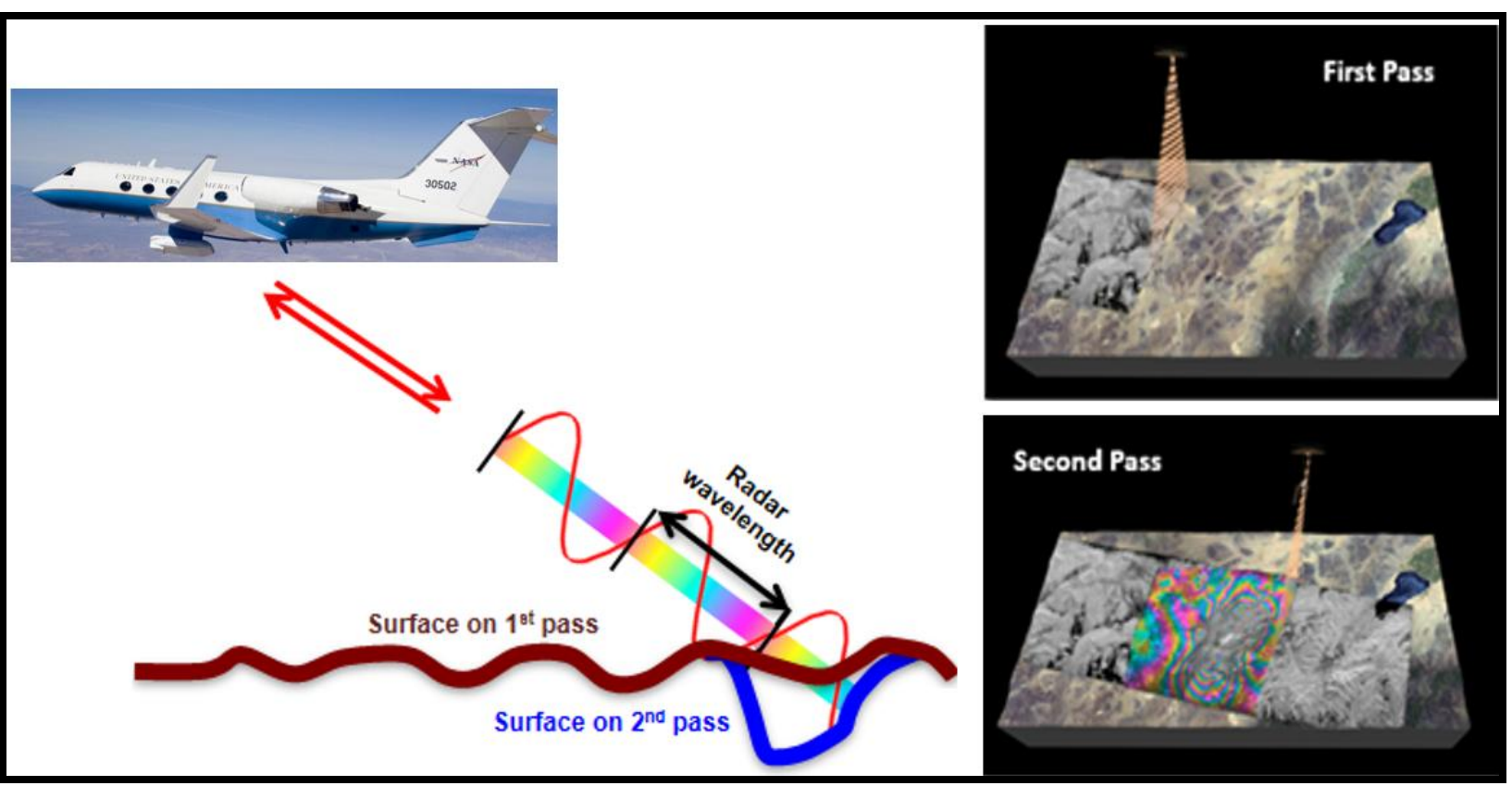

216 Figure 5. The basic principle of InSAR is demonstrated in this figure. When the radar instrument

217 is flown over a patch of ground the first time (first pass), it transmits microwave pulses towards

218 the surface of the Earth and receives the reflected echo of the radar signal. The incident and

219 reflected signal can be compared in terms of change in amplitude and phase. During the second

220 pass, the radar instrument flies again over the same region to measure new reflection and change

221 of range (distance between instrument and land surface) along line-of-sight direction through the

222 relative change in the phase of the returned signal. (Image credit: Paul A. Rosen)

We generate stacks of co-registered single-look complex data (SLCs) with the standard 225 UAVSAR processor. While selecting SLCs to be used for our analysis, we take into account 226 standard data quality metrics to evaluate potential acquisition errors associated with airborne 227 InSAR data, including positional accuracy of the flight track (aircraft motion), nadir return in 228 images and image decorrelation. We do not include any SLCs for which more than $20 \%$ of the 229 flight track is outside with respect to the reference tube (the percentage of flight track outside the 
230 tube for the SLCs used in this analysis ranged from $0 \%$ to $8.9 \%$, with an average value of $0.5 \%$ ).

231 In addition, we apply network deramping (described later in the manuscript) to further correct for

232 aircraft motion. Furthermore, we use a low coherence threshold mask (also described later in the

233 manuscript) to exclude areas with excessive image decorrelation. Finally, we use these selected

234 SLCs to form interferograms (containing magnitude and wrapped phase information) in radar

235 coordinates (slant-range/azimuth). data for this study. The single-look interferograms are down-sampled (multi-looked) by a factor

241 of the noise reduction, down-sampling by a factor of 3 (slant range) x 12 (azimuth) best resolved

242 the higher coherence finer scale features and gave good interferometric phase signals. The 243 interferometric coherence (statistical estimate of change between different acquisitions) is 244 calculated as the normalized magnitude (zero to one) of the complex correlation image following 245 the spatial averaging to reduce noise. Figure 7 shows the pairs of acquisitions used for forming 246 interferograms for both lines. As a general rule, data from flights spaced 1 to 4 months apart 247 were used for generating the interferograms in order to reduce the effect of temporal 248 decorrelation, in addition to annual summer-to-summer interferograms. Each acquisition is used 249 for forming a minimum of 5 interferograms. 


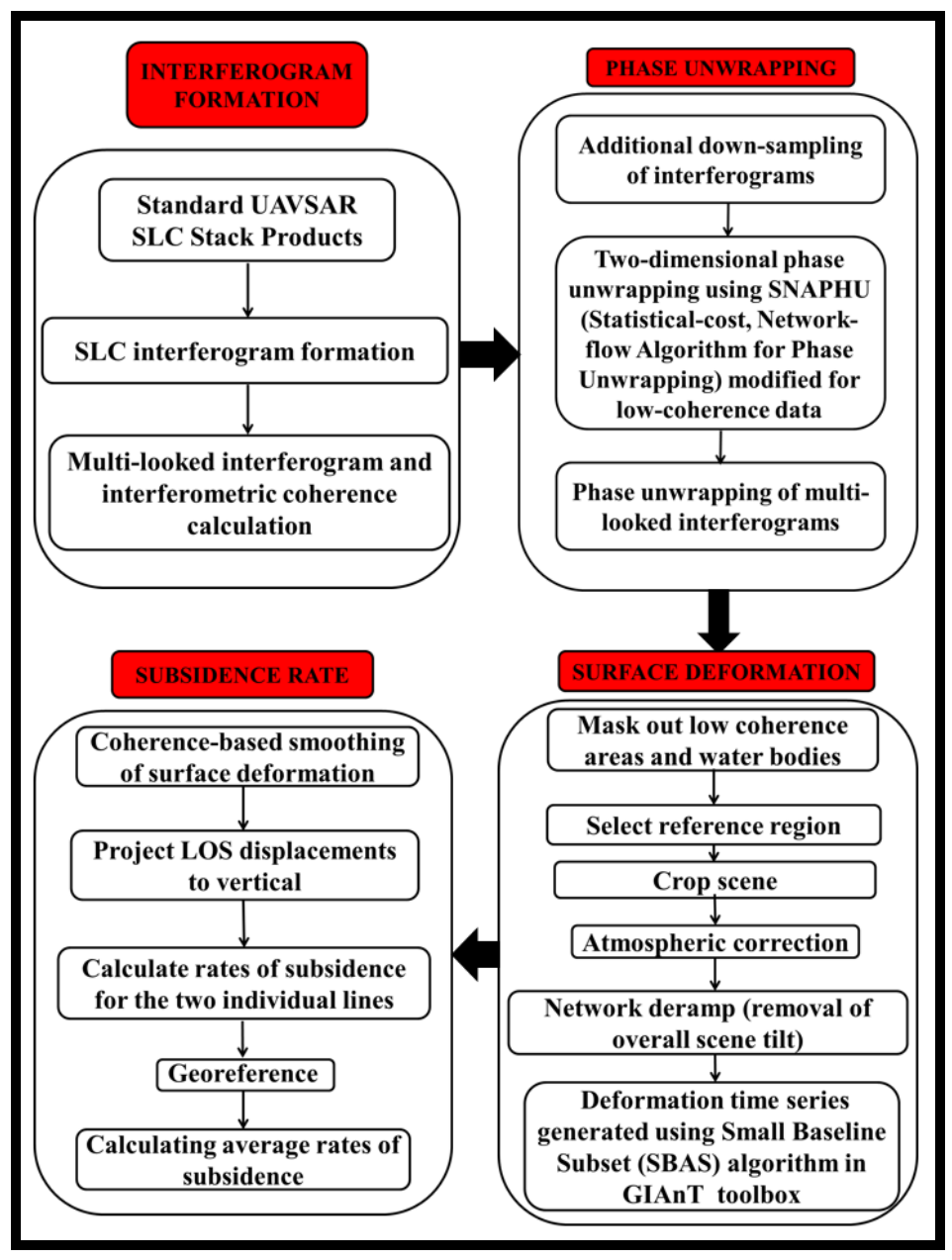

252 Figure 6. Overview of processing methodology 


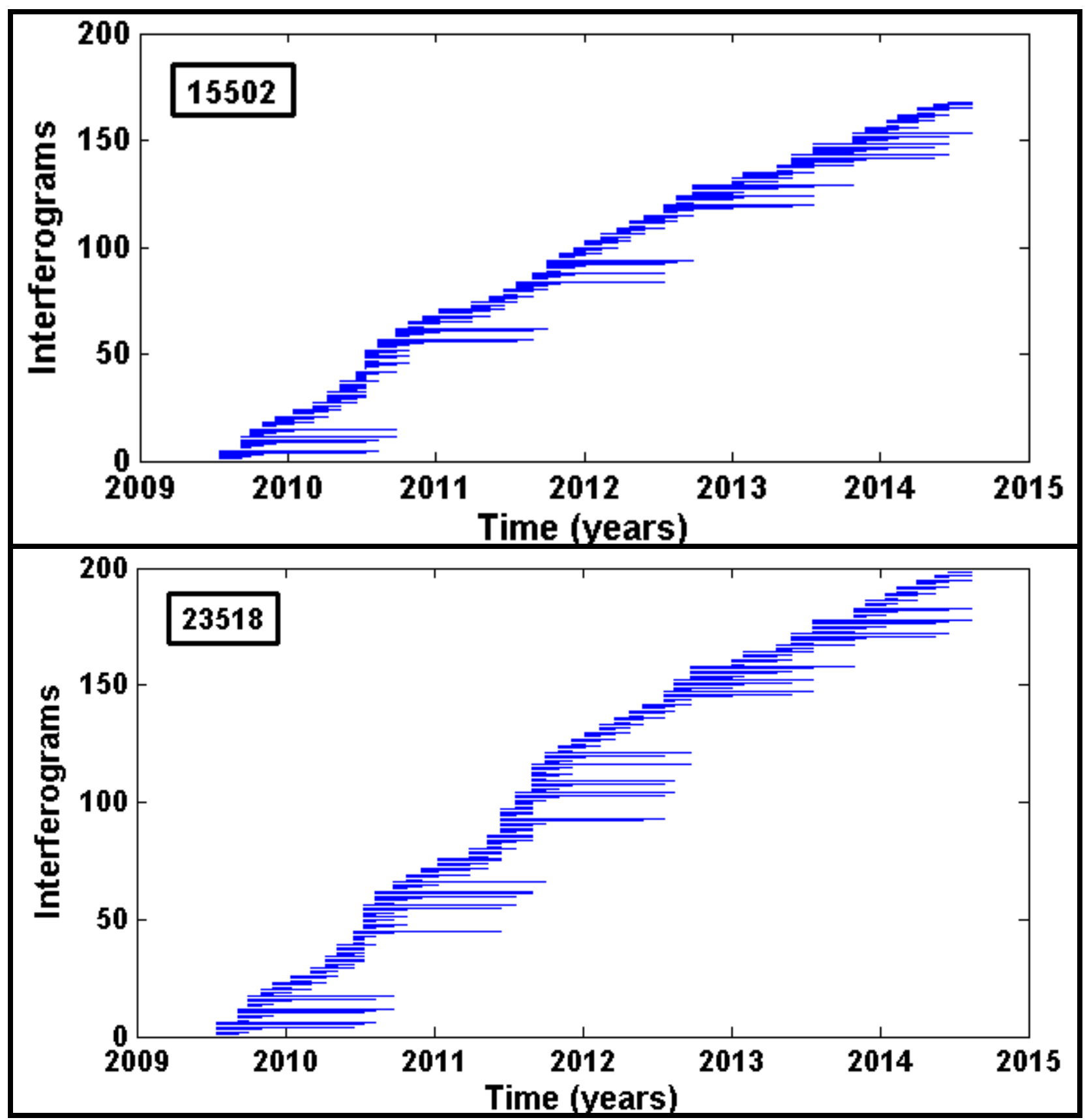

256 Figure 7. Pairs of acquisitions used for forming interferograms for both lines (15502 and 23518)

257 are shown in this figure. 47 data acquisitions taken by the UAVSAR were utilized to generate

258168 interferograms for line 15502, and 50 acquisitions were used to generate 198 interferograms

259 for line 23518. Each acquisition is used for forming a minimum of five interferograms. 
The next major step in the data processing is phase unwrapping. We further down-sample

262

263

264

265

266

267

268

269

270

271

272

273

274

275

276

277

278

279

280

281

282

283

the $3 \times 12$ interferograms by an additional $3 \times 3$ to obtain spatially filtered interferograms. We use these interferograms to create low resolution unwrapped phase masks, which are then used to determine the correct wrap for the $3 \times 3$ pixels in the full resolution interferograms. We carry out two-dimensional phase unwrapping on the 9x36 multi-looked interferograms using the SNAPHU algorithm (Statistical-cost, Network-flow Algorithm for Phase Unwrapping) (Chen and Zebker, 2001), modified as follows for low-coherence data. In order to deal with the large amount of low coherence regions in the images, which would otherwise lead to many disconnected regions and incorrect unwrapping, we make the assumption that the deformation in low coherence areas is sufficiently slow that more than one phase wrap does not occur between the low coherence pixel and its nearest high coherence neighbor. With UAVSAR's wavelength of $23.8 \mathrm{~cm}$ and the short repeat interval providing greater coherence as compared to shorter wavelength radar platforms, this is valid in an area with slow subsidence like our study area. Based on this, before using SNAPHU to phase unwrap the scene, we replace the phase values in low coherence areas by the phase of the nearest high coherence neighboring point. Thresholds defining "low" and "high" were determined experimentally, with 0.40 and 0.45 generating consistent, low error, results for all scenes. Following phase unwrapping with SNAPHU, the original phase $+\mathrm{N} \times 2 \pi$ of the low coherence pixel is restored, with the $2 \pi$ multiple selected to put the phase on the same wrap as the nearest high coherence neighbor.

81 We utilize the Small Baseline Subset (SBAS) (Berardino et al., 2002) time-series interferometric method implemented in the Generic InSAR Analysis Toolbox (GIAnT) (Agram et al., 2012, 2013) to calculate ground surface deformation from unwrapped phase. Before 
284 starting the time-series analysis, we generate a mask to eliminate very low coherence areas and 285 water bodies in the region based on three inputs that are calculated for each pixel in the image: a 286 minimum average coherence threshold, where the average is calculated over all the 287 interferograms; a minimum threshold for the coherence that must be satisfied for at least a 288 specified percentage of the interferograms; and a water mask generated using water body GIS 289 shapefiles (vector outlines) from the USGS National Hydrography Dataset (Simley and Carswell, 290 2009). The minimum average coherence threshold (0.3) is selected based on the average 291 coherence of the water in the scene. The percentage criteria for the coherence of individual 292 interferograms (coherence $>0.35$ for at least $40 \%$ of the interferograms) is selected to eliminate 293 areas that are not coherent frequently enough to obtain good results over the five year interval of 294 our study. This eliminates saturated and frequently flooded land areas. Next, we select regions 295 with minimal phase change and high coherence as the phase reference. To identify appropriate 296 potential reference regions, we generate maps of minimum, maximum and average coherence for 297 the entire scene and extract pixels with consistently high minimum coherence (>0.5). We avoid 298 selecting areas with known time-varying elevations, particularly geologic historic fault lines and 299 man-made structures like electrical transmission lines, which can expand/contract with changing 300 temperatures. We evaluated multiple reference regions for this study and selected the concrete 301 base of one of the electric transmission line towers $\left(\sim 38.07^{\circ} \mathrm{N}, 121.71^{\circ} \mathrm{W}\right)$ as a reference. The 302 average coherence at this location was 0.88 . Figure 8 shows the phase reference and locations of 303 electrical transmission towers used in previous subsidence measurements and an extensometer in 304 operation during our study and used as validation for our UAVSAR measurements, as described 305 later in this manuscript. The scene is then cropped to the geographic boundaries of Sherman 306 Island only. Figure 9 shows a typical example of an interferogram with magnitude and phase 
307 information, the associated interferometric coherence and the mask for one of the lines covering 308 Sherman Island (15502).

309

310 


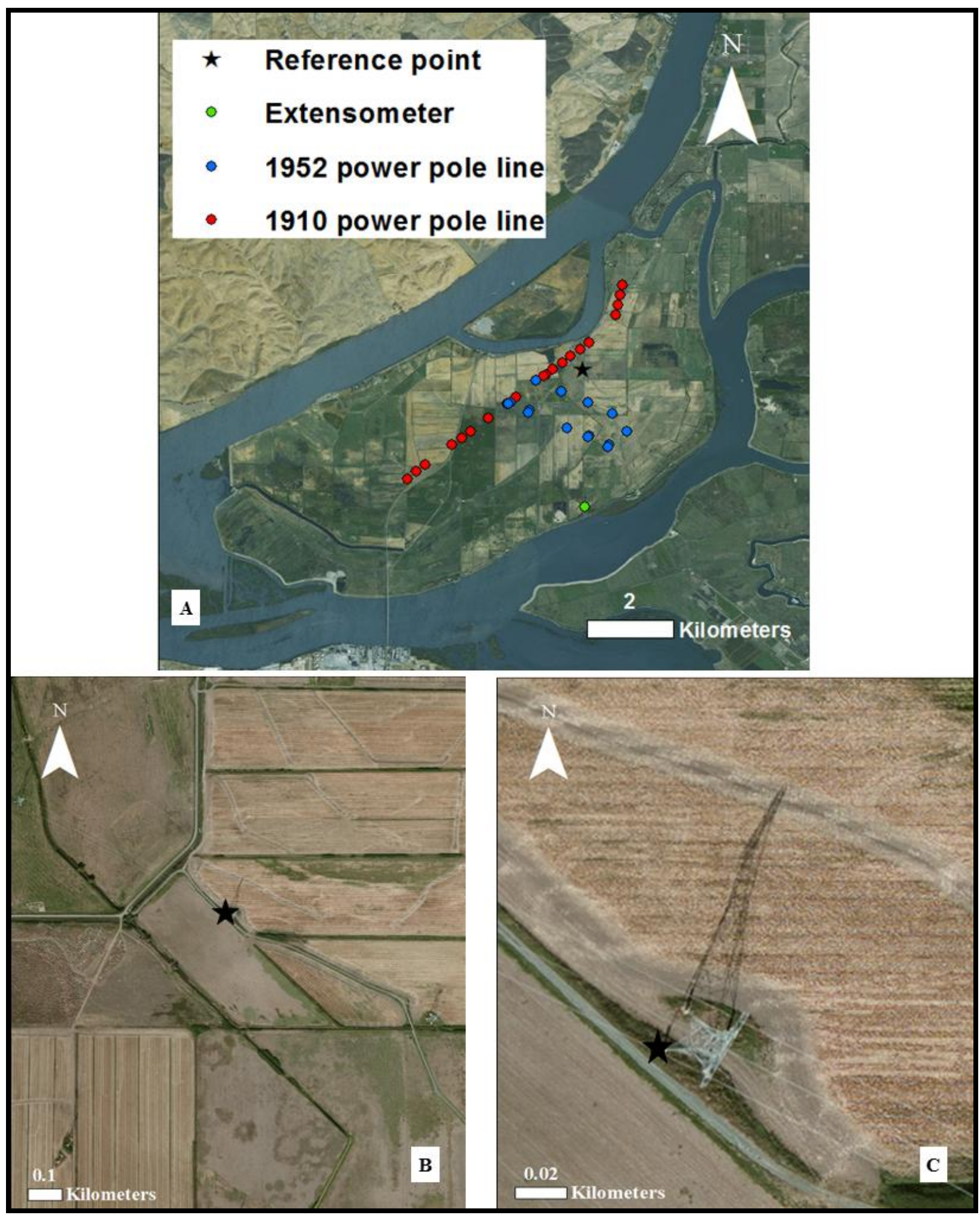

312 Figure 8. [A] Location of the reference point used for this study in Google Earth® optical 313 imagery. The reference region is at the base of one of the electric transmission line towers 
$314\left(\sim 38.07^{\circ} \mathrm{N}, 121.71^{\circ} \mathrm{W}\right)$ located within Sherman Island. The locations of electrical transmission

315 power lines used for comparison with previous studies are also indicated in panel A. The

316 transmission line built in 1910 cuts across Sherman Island from west to east, and the

317 transmission line built in 1952 cuts across from north to south. Location of the extensometer that

318 is used for providing ground-truth for UAVSAR measurements is also shown. Close-up views of

319 the reference region location at increasing resolutions are shown in the bottom left [B] and

320 bottom right [C] panels.

321

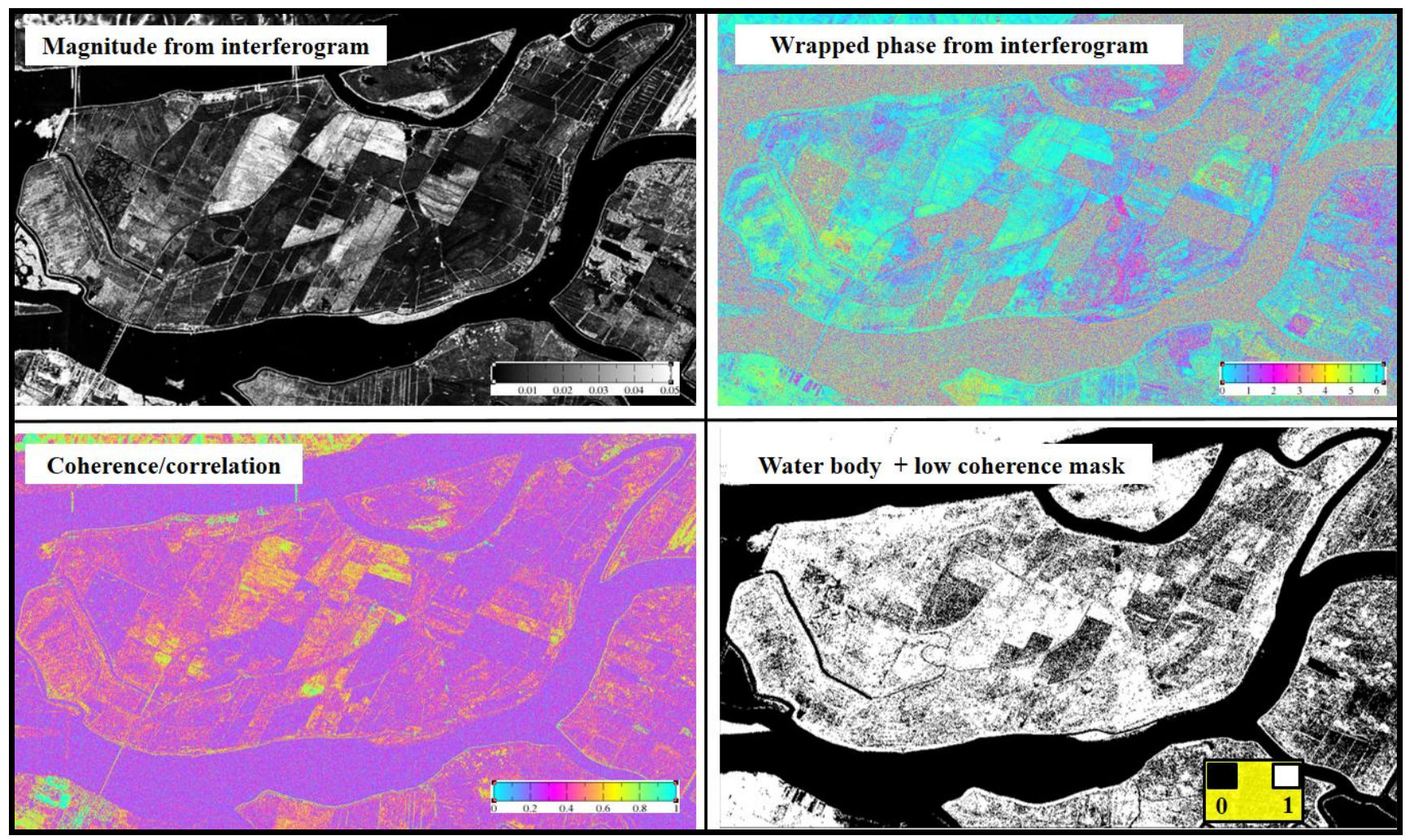

323 Figure 9. Example of an interferogram with magnitude (upper left) and phase (upper right)

324 information, coherence (lower left) and water mask (lower right) for line 15502. Each of the sub-

325 figures is shown in radar (range/azimuth) coordinates. Line ID: 15502, Dates of acquisition:

326 2010-09-25 and 2010-10-25, Temporal baseline: 31 days. 
We utilize atmospheric data from NOAA's NARR (North American Regional Reanalysis,

329 National Oceanographic and Atmospheric Administration) weather model for North America

330 (Mesinger et al., 2006), to correct for effects of tropospheric delay. This atmospheric model

331 provide estimates of air temperature, atmospheric pressure and humidity as a function of

332 elevation at a spatial resolution of $30 \mathrm{~km}$ and temporal resolution of 3 hours. This three-

333 dimensional distribution of atmospheric variables is used to determine the atmospheric phase

334 delay correlated with topography for each pixel of each interferogram (Doin et al., 2009; Jolivet

335 et al., 2011; Jolivet and Agram, 2012).

Next, we use GIAnT's network de-ramping algorithm for estimating flight path variation

338 effects on interferograms, which evaluates a scene tilt in a network sense, independently on each

339 interferogram using a least-squares scheme (Biggs et al., 2007; Cavalie et al., 2007, 2008; Lin et

340 al., 2010; Agram et al., 2012; Jolivet et al., 2012). This tilt is induced by small errors in the

341 measured aircraft flight position. The tilt is expressed as a two-dimensional plane, ax $+b y+c$,

342 where $\mathrm{a}, \mathrm{b}$ and $\mathrm{c}$ are the fit parameters and $\mathrm{x}$ and $\mathrm{y}$ are fractional sample and line location in the

343 interferograms. Then, the SBAS algorithm, modified for coherence weighting, is used to

344 calculate time series of cumulative surface deformation along the line-of-sight direction.

The cumulative displacement results are adaptively smoothed based on average

347 coherence, with higher coherence points undergoing lesser averaging and only pixels of similar 348 coherence being averaged together. The smoothed displacements along the line-of-sight are then 349 projected to subsidence/uplift assuming that there is no horizontal displacement component. 350 Although this could introduce minor artifacts in areas with steep fringe gradients (Bawden et al, 
351 2001), that is not a problem in our study area. The six closest GPS stations from the Plate

352 Boundary Observatory (PBO) network, which are distributed around the edge of the Delta, all

353 measure average horizontal velocity of $1.3-1.4 \mathrm{~cm} / \mathrm{yr}$, indicating the Delta to be moving

354 northwest with respect to stable North America (reference frame NAD08) with near-uniform

355 velocity. By choosing a phase reference within Sherman Island, we remove most of the effect of

356 horizontal tectonic motion. Thus, the assumption that the interferograms measure predominantly

357 the vertical component of the displacement field is reasonable. Exceptions would be in areas

358 with topographic relief, and might occur on the slopes of the levees as discussed later.

359

Uncertainties in the calculated subsidence are estimated by performing a Jacknife test

361 (Efron and Stein, 1981), a variation of the bootstrap resampling technique, using subsets

362 generated on the basis of SAR acquisitions. These uncertainty estimates are used to weight the

363 cumulative subsidence values at each time step for calculating rates of subsidence. We calculate

364 rates of subsidence from the projected subsidence measurements by estimating a least-squares

365 linear fit to the time-varying subsidence measurements between July 2009 and August 2014 for

366 each pixel. We then georeference (convert data from radar coordinates to geographic

367 coordinates) the results obtained from the two UAVSAR lines covering Sherman Island and

368 calculate the linear subsidence rate across Sherman Island and the uncertainty (random error) in

369 the calculated rate. Finally, we calculate the average of the subsidence and subsidence rates for

370 the two lines. For pixels that are masked in one line but not the other, the value used is the 371 subsidence/subsidence rate for the unmasked pixel. 
374 processing can lead to decorrelation, and systematic errors resulting from effective path length

375 variations over the scene can result in biases (Hanssen, 2001; Reeves et al., 2014). Data

376 acquisition and processing errors include baseline decorrelation, doppler centroid decorrelation,

377 volume scattering decorrelation, thermal or system noise, temporal terrain decorrelation and

378 processing induced decorrelation (from co-registration and interpolation). The effect of all of

379 these errors is contained in the coherence parameter and we account for them through various

380 techniques. We only include those pixels in our analysis for which coherence averaged across all 381 interferograms is greater than 0.3 and overall coherence is greater than 0.35 in at least $40 \%$ of the 382 interferograms. This is used as a threshold for identifying water bodies, flooded areas, and areas 383 with too much disturbance to yield reliable subsidence measurements with InSAR. We modify 384 the SNAPHU phase unwrapping algorithm for low-coherence data. We also perform coherence 385 weighting on the cumulative displacements generated by the SBAS calculation. We undertake 386 coherence-based smoothing of the cumulative displacements and use the uncertainties in 387 subsidence as weights while calculating rates of subsidence. All of these measures minimize the 388 effect of any random errors that would lead to decorrelation. Microwave path length variations 389 can occur as a result of aircraft motion effects or tropospheric delay effects. We account for these 390 errors by including network de-ramping and atmospheric correction in our calculations, as 391 described earlier in this section.

To estimate the systematic error in our analysis, we modified the mask that is used for 394 cropping out low coherence areas and water bodies to use a different minimum average 395 coherence threshold (0.285 compared to the previously used 0.3$)$ and no requirement on the 
396 percentage of interferograms exceeding a minimum coherence threshold. We compared the

397 average subsidence rate calculated using the two masks for the whole island, and estimated the

398 systematic uncertainty as the Root-Mean-Square-Error (RMSE) of the difference. Using this

399 procedure we determined our systematic uncertainty to be $0.3 \mathrm{~cm} / \mathrm{yr}$.

400

401 4. InSAR-derived subsidence across Sherman Island

402 The time-series interferometric approach described above enabled us to calculate cumulative

403 subsidence and uncertainty estimates across Sherman Island, as measured on August 14, 2014

404 with respect to the first acquisition on July 18, 2009. Results from both UAVSAR flight lines

405 (15502 \& 23518) indicate subsidence of 0-25 cm over the five years of data acquisition, with 5.8

$406 \pm 1.4 \mathrm{~cm}$ being the average subsidence observed across the island in the areas that were not 407 masked.

408

409

Overall, we calculate an average subsidence rate of $1.3 \pm 0.2 \mathrm{~cm} / \mathrm{yr}$ (with $0.3 \mathrm{~cm} / \mathrm{yr}$

410 systematic uncertainty), ranging between $0-5 \mathrm{~cm} / \mathrm{yr}$ across the island, as observed in Figure 10A,

411 which shows subsidence rates derived from a linear fit to the subsidence vs. time. We observe a

412 large-scale trend of greater subsidence rates in the central portion of the island, and along the

413 levees on the western shoreline. This observation could be attributed to land use (Figure 3C) and

414 associated water management practices. Most of Sherman Island is used as pasture area, except

415 for the agricultural fields in the central regions of the island, which are used for growing crops.

416 Variable depth to groundwater resultant from variations in drainage depth could be responsible

417 for the observed island-wide spatial variation of subsidence. This association between water

418 table depth (and hence the depth of the unsaturated zone) and subsidence has been suggested by 
419 other researchers also (Stephens et al., 1984; Deverel and Leighton, 2010). Oxidative subsidence

420 is inversely correlated with depth to groundwater (Stephens et al., 1984). The depth of the

421 unsaturated zone influences the extent of oxidation. The greater the depth of the unsaturated

422 zone, the larger is the subsidence rate. We find soil type (and hence percentage of organic matter

423 content) to be a factor affecting large-scale subsidence across Sherman Island. Areas dominated

424 by soils with higher organic content (like Rindge mucky silt loam, Gazwell mucky clay) exhibit

425 generally higher subsidence rates compared to areas with lower organic content soils (like

426 Sailboat silt loam, Columbia fine sandy loam) (Figure 11A). We also observe a trend of higher

427 subsidence rates for lower elevations (Fig. 11B). For most soils (except Sailboat, Sailboat

428 Variant and Egbert), soil type and land elevation are found to be correlated. Higher organic

429 content soils are observed to be generally associated with lower elevations, which could indicate

430 ongoing subsidence over a relatively longer time period (Fig. 11C). Greater subsidence along the

431 western shoreline levees may be associated with multiple repairs involving addition of fill

432 material that have been carried out over the past few years.

Also plotted is the estimate of uncertainty (random error) in the subsidence rate (Figure

434 10B). Difference between the subsidence rates derived from the two lines is largest in some areas

435 along the levees and in southern Sherman Island (Figure 10C). In areas along the levees, this

436 could indicate a breakdown in the assumption that there is no horizontal component to the line-

437 of-sight movement, particularly on levee slopes. For example, in the area shown in Figure 12a

438 marked by the yellow star, there are slanted telephone poles. In inland areas, where the two lines

439 differ more than the average, temporal change of scatterers could be responsible for the observed

440 difference between the two lines. Also, it is possible that the three hour temporal resolution of

441 the atmospheric model used does not differentiate between atmospheric conditions during 
442 acquisitions for the two lines made on the same day within an hour or so, and this could be a

443 contributing factor. Therefore, we consider our subsidence results in such regions to be poorly

444 constrained.

445 

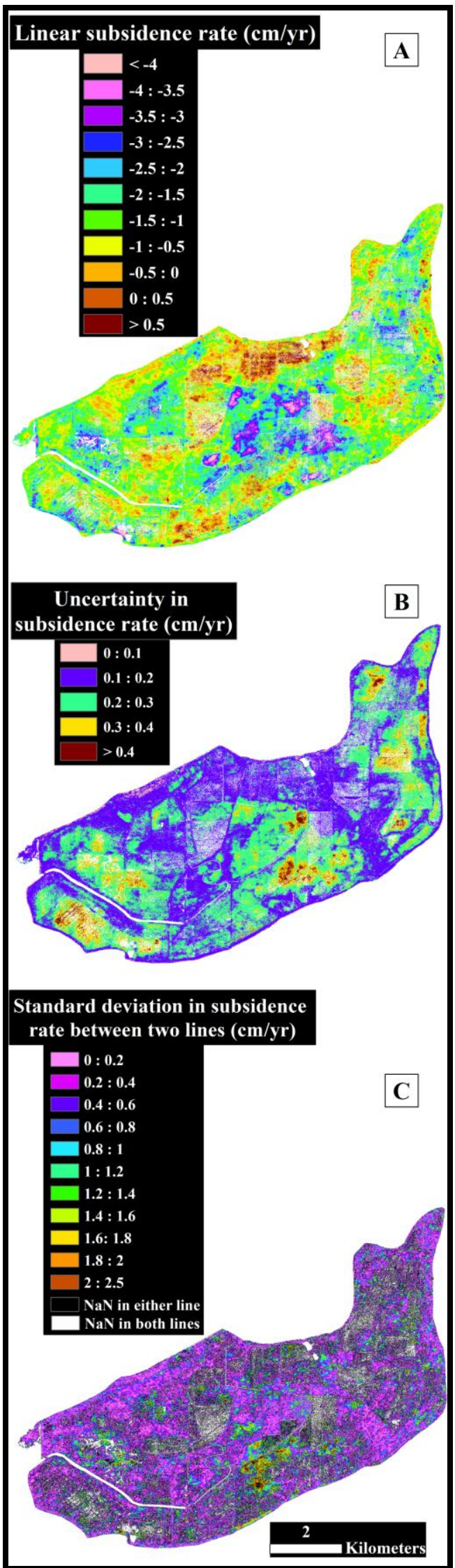
Figure 10. [A] Subsidence rates on Sherman Island derived from a weighted linear fit to the cumulative subsidence vs. time, from July 18, 2009 to August 14, 2014. [B] Uncertainty in

449 subsidence rate $(\mathrm{cm} / \mathrm{yr})$. [C] Standard deviation in the subsidence rates calculated from the two UAVSAR lines, 15502 and 23518. Black pixels in this image indicate the ones for which 451 subsidence was calculated from one line only.
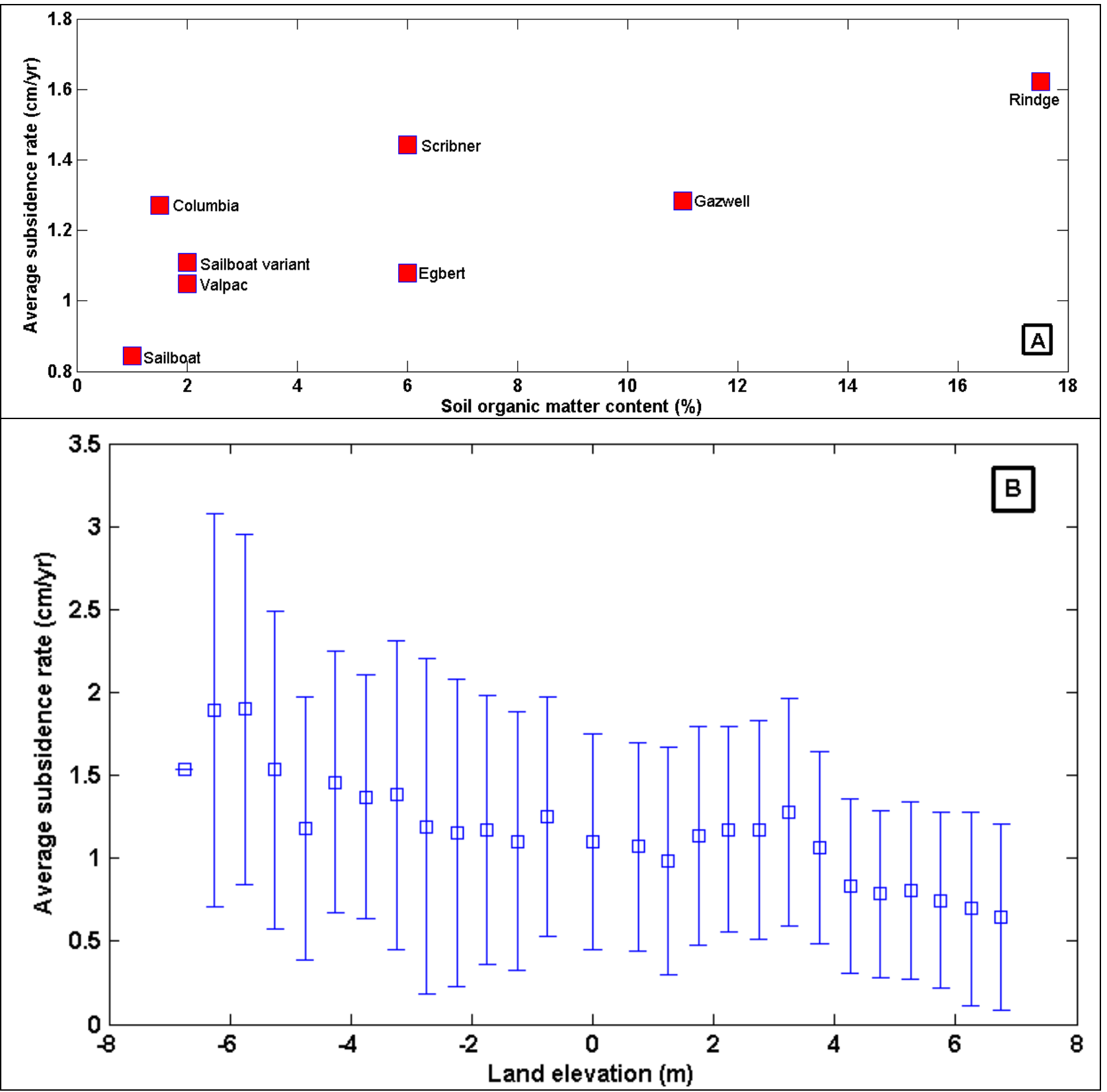


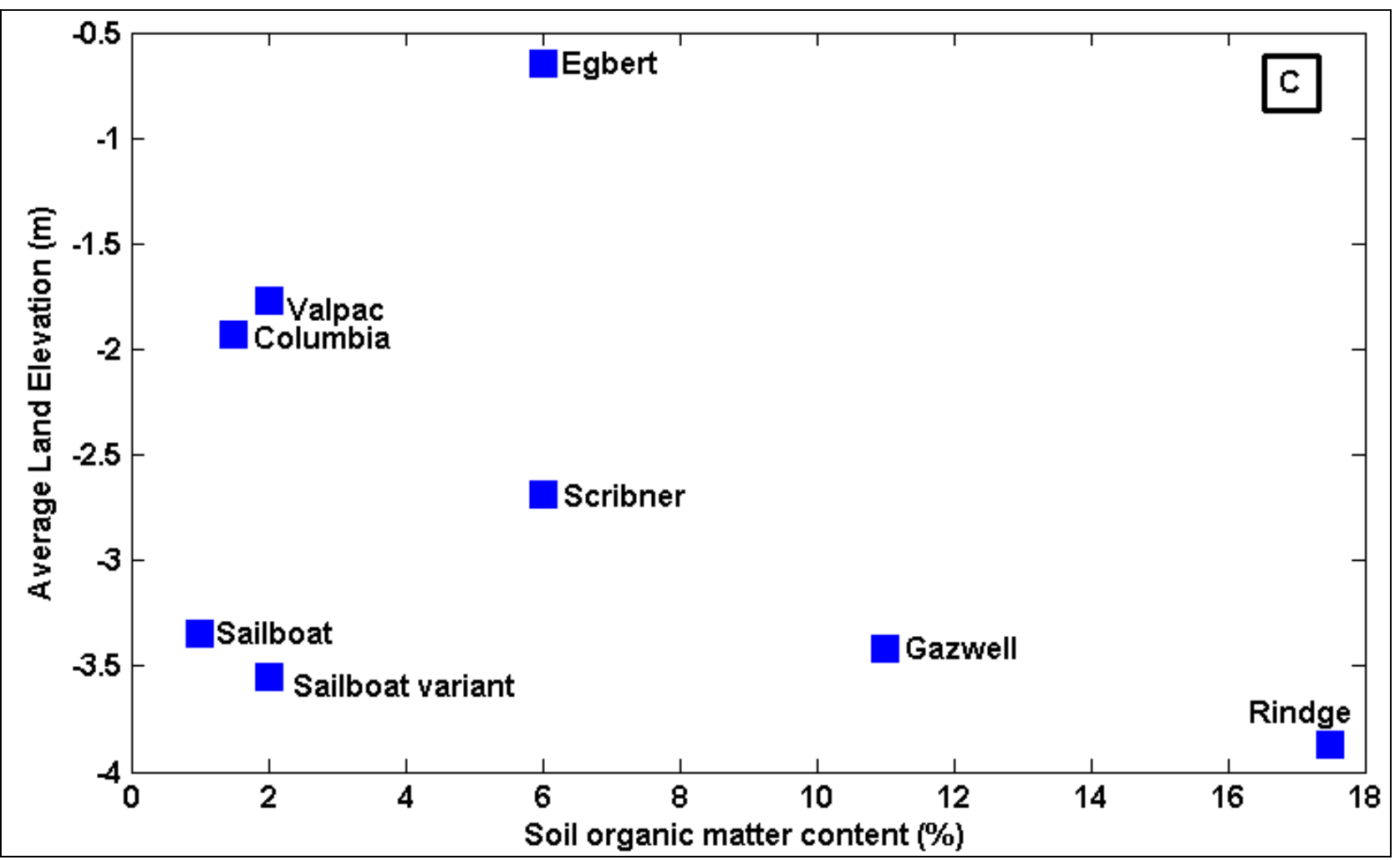

Figure 11. [A] Variation of average subsidence rates with soil type (organic matter content)

454 across the whole island is shown. Greater organic matter content in soils is generally associated 455 with higher average subsidence rates. [B] Higher subsidence rates are observed for lower 456 elevations. [C] Correlation is observed between soil organic content and elevation, with higher 457 organic content soils being generally associated with lower elevations (exceptions include 458 Sailboat, Sailboat Variant and Egbert soil types). Land elevations reported in Figs. 11B and 11C 459 have been measured with respect to vertical datum NAVD88 (CA DWR, 2007b).

On smaller scales, we observe multiple high subsidence features on Sherman Island 462 (Figure 12). The first feature is located in southwestern Sherman Island and has experienced 463 almost $25 \mathrm{~cm}$ of subsidence in the five years since UAVSAR began acquiring data over the 464 island (indicated by a yellow star in Figure 12a). Optical imagery over the feature shows a scour 465 pond that had formed after the levee breach of 1969 and a dredge disposal site (used for 
466 providing source material for repairing/maintaining levees). The section of the levee in this area

467 has been repaired multiple times and the observed subsidence is presumably related to repair-

468 induced loading on the previously-unloaded organic soils in the new setback levee section due to

469 the addition of fill material during repair work. For contrast, we show in Figure 12a subsidence

470 vs. time at a nearby site (indicated by the red star) that is roughly the same distance inland from

471 the levee. Here we see modest subsidence combined with seasonal oscillations. This example

472 demonstrates how changes in land elevation from one season to the next can be significant

473 enough to make the timing of the elevation measurement important. The UAVSAR data

474 analyzed for this study cover the time period from July 2009-August 2014, thus minimizing the

475 effect of seasonal oscillations in land elevation, in calculating the rate of subsidence. In Figure

$47612 \mathrm{~b}$, we show a high subsidence feature in the central portion of the island, for which the

477 temporal trend of subsidence consists of a mixture of seasonal oscillations overlain with an

478 overall decrease in elevation. This subsidence feature overlaps with a mix of cultivated and

479 fallow land, as observed in the corresponding visual imagery. In this case, the variation of soil

480 moisture and water table depth between land used for agriculture and land left bare could have a

481 direct impact on the location of the subsidence feature. Figure 12c shows a feature in the

482 northeastern section of the island, for which there is some indication of correlation between the

483 shape of the feature and the variation of soil type and organic matter content, although the

484 feature shape does not exactly follow the soil type variation, which could be in part due to the

485 coarse resolution of the soil type map available. Finally, the northeastern 'tail' section of the

486 island shows greater subsidence in the central portion compared to the edges of the section, close

487 to the water channels and the remnant natural levees of the island. As shown in Figure 12d, a 
488 combination of soil type and topography variation is likely contributing to the variation of 489 subsidence observed here.

490 


\section{Linear subsidence rate $(\mathrm{cm} / \mathrm{yr})$}

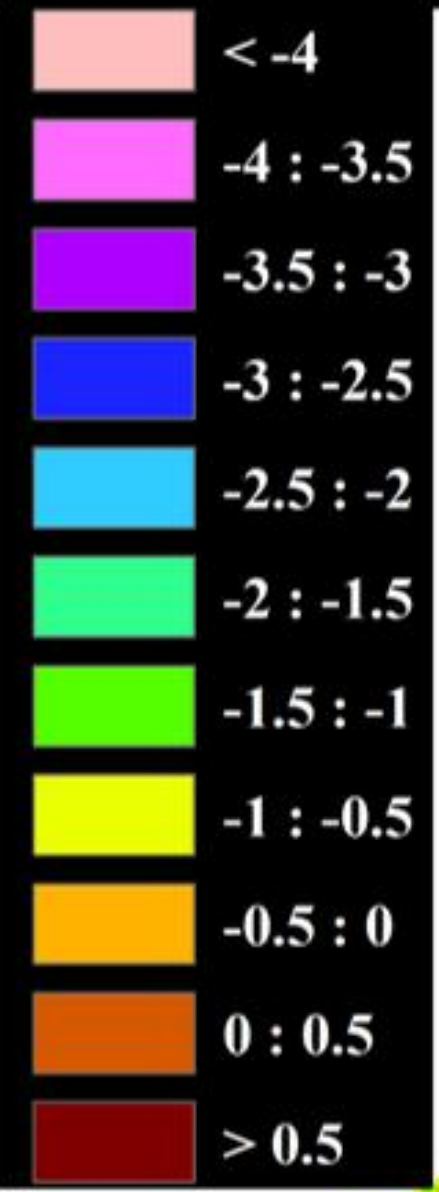

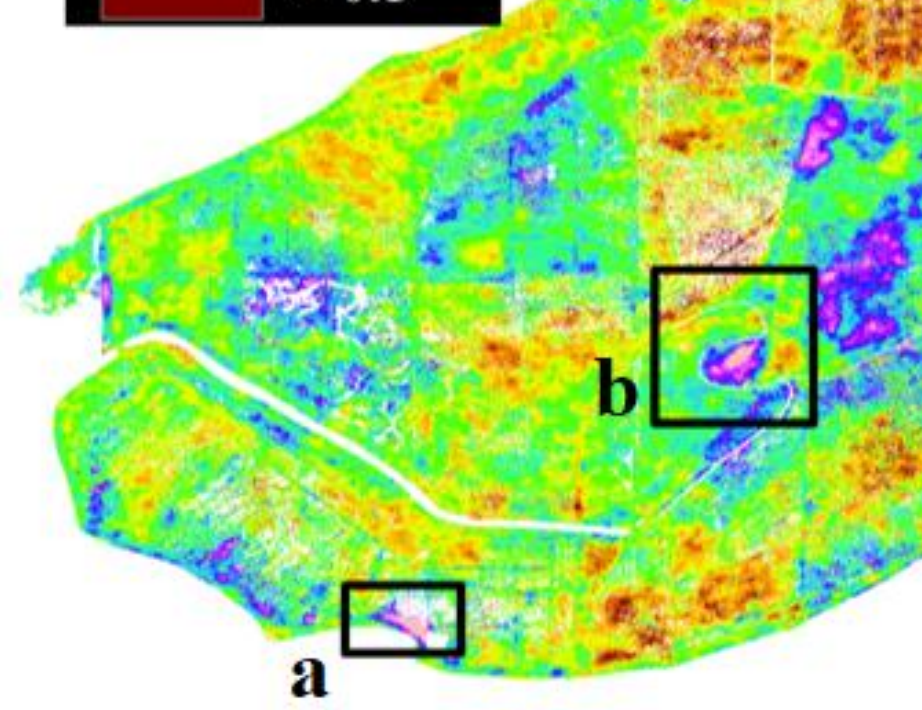

Kilometers 


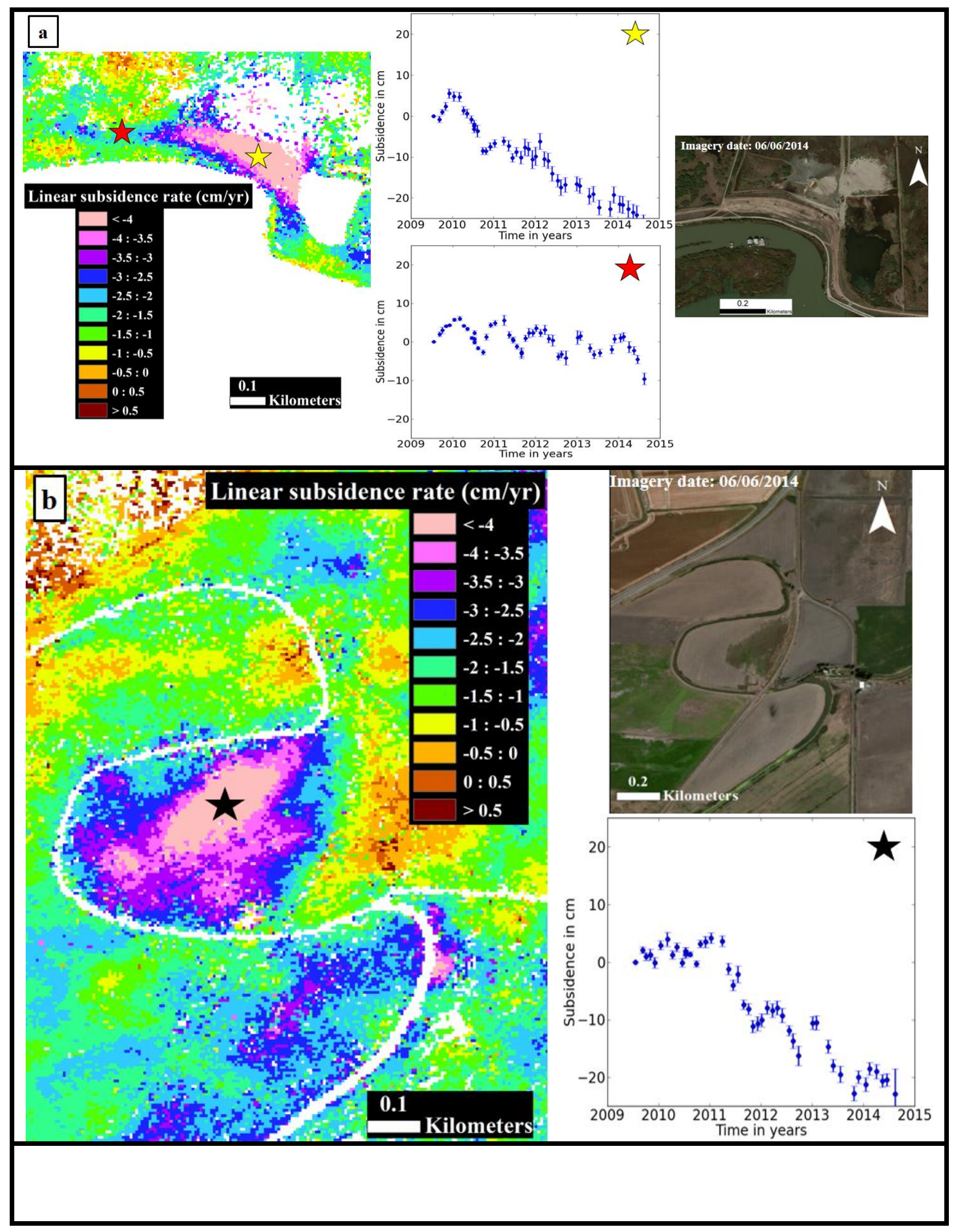




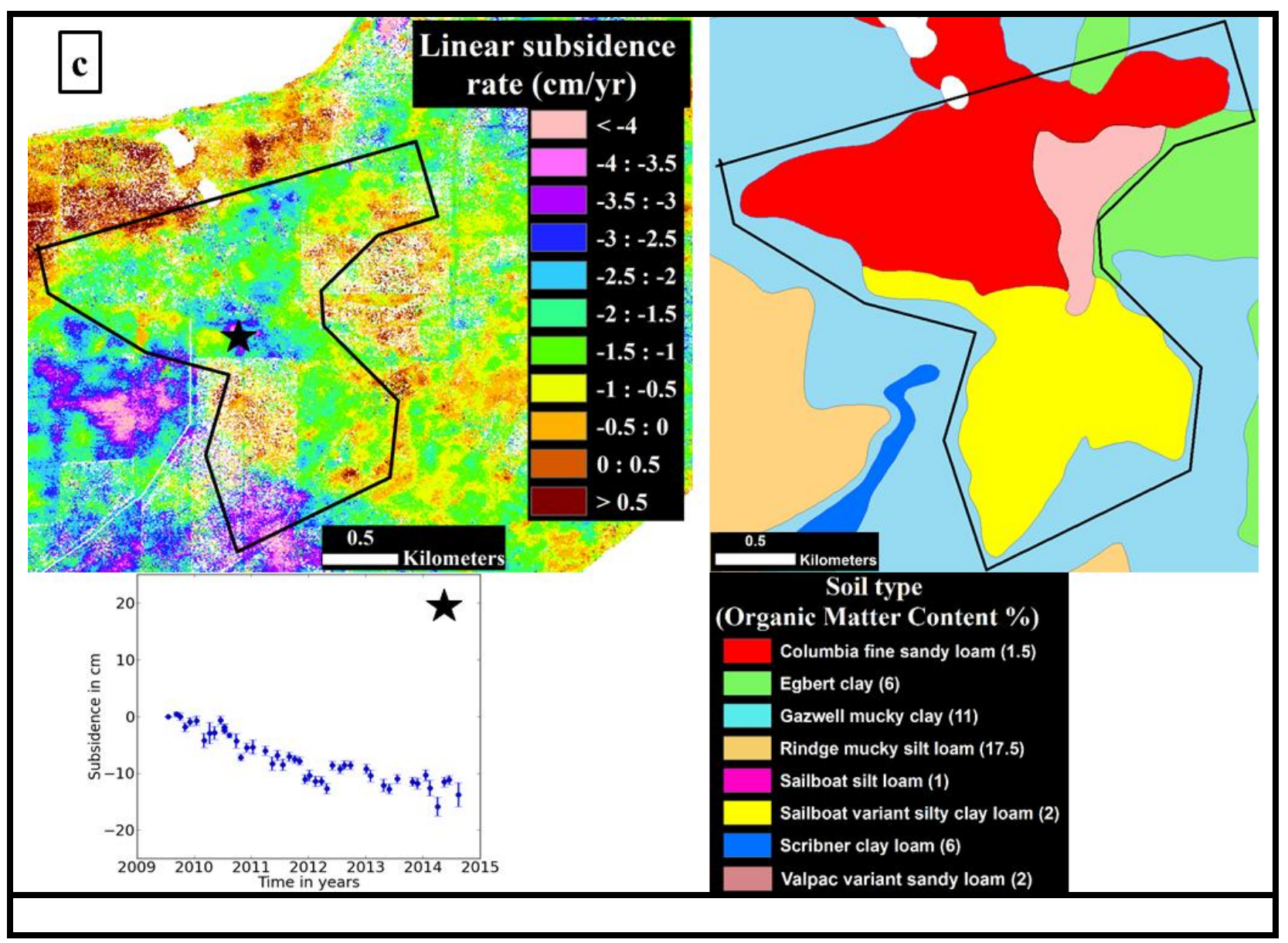




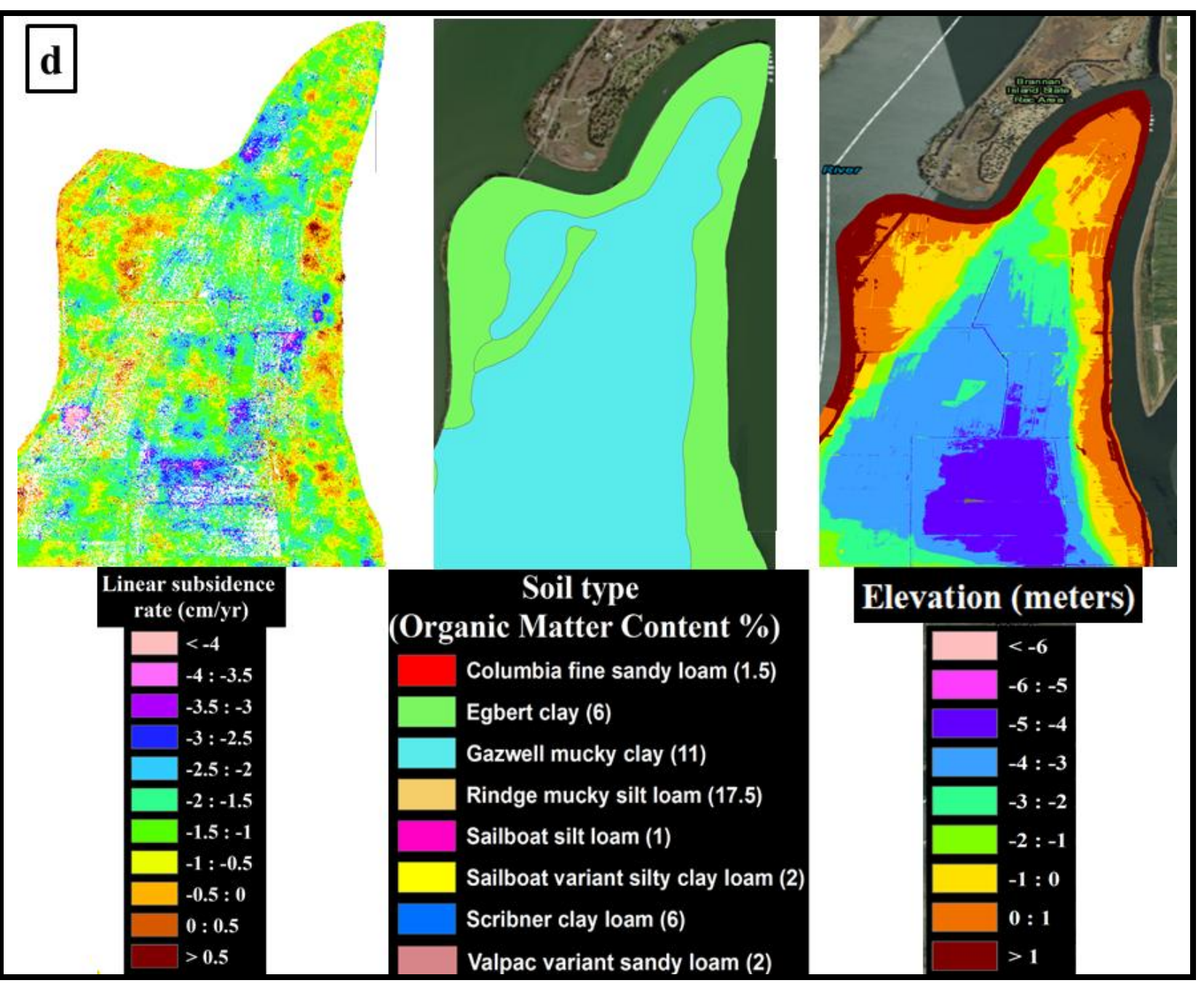

493 Figure 12. Examples of small-scale subsidence features observed across Sherman Island with 494 UAVSAR are shown in this figure. The top panel shows locations of these features outlined in 495 black rectangles. (a) The yellow star shows an area adjacent to the levee in southwestern 496 Sherman Island that experienced $\sim 25 \mathrm{~cm}$ of subsidence over the five years of our study. Optical 497 imagery of the feature shows a scour pond and a dredge disposal site. The red star shows 498 subsidence vs. time for a nearby point that does not exhibit rapid subsidence, but instead slow 499 subsidence with much larger seasonal oscillations in land elevation. (b) Subsidence feature in 500 central Sherman Island that shows a mix of subsidence and seasonal oscillation in its elevation 501 trend. (c) Subsidence feature in northeastern Sherman Island that is partially correlated with 
502 variation of soil type. (d) The 'tail' section in northeastern Sherman Island shows subsidence

503 variation that generally follows the variation of topography and soil type.

504

We compare our results for subsidence rates during the period 2009-2014 to previous

506 subsidence measurements on Sherman Island. Multiple past studies have measured soil loss

507 against concrete bases of electrical transmission towers to estimate subsidence at a few locations

508 across Sherman Island. Rojstaczer et al. (1991) and Rojstaczer and Deverel (1995) reported 509 subsidence rates of $2.3 \mathrm{~cm} / \mathrm{yr}$ and $1.5 \mathrm{~cm} / \mathrm{yr}$ from 20 and 12 power pole measurements taken 510 from power pole lines crossing Sherman Island from west to east and north to south, 511 respectively. Deverel and Leighton (2010) concluded Sherman Island to be subsiding at an 512 average rate of $1.3 \mathrm{~cm} / \mathrm{yr}$, based on measurements from 13 towers from the North-South crossing 513 transmission line across the island. Deverel and Rojstaczer (1996) installed an extensometer in 514 southern Sherman Island, which yielded a subsidence rate of $0.46 \mathrm{~cm} / \mathrm{yr}$. Brooks et al. (2012b) 515 and Glennie et al. (2013) developed a customized LiDAR system mounted on a balloon and flew 516 it over a section of the southwestern levee of Sherman Island. By comparing their observations 517 with the LiDAR survey of 2007-08 conducted by the CA DWR, they calculated 10s of 518 centimeters of subsidence across and around the levee. Following the approach of previous 519 studies for calculating subsidence at the base of the electric transmission line towers, we selected 520 four regions within 100 meters of the base of each power pole. We calculated an average of the 521 subsidence rates at these four neighboring regions to estimate the subsidence rate at each power 522 pole. Our results are comparable in magnitude to the power pole, extensometer and LiDAR523 based measurements from previous studies. Tables 2 and 3 show a comparison of our results 524 with individual power pole measurements reported by Rojstaczer et al. (1991), Rojstaczer and 
Deverel (1995) and Deverel and Leighton (2010). Figure 8 shows the location of the electric transmission line towers used for this comparison.

Table 2. Comparison of UAVSAR-derived subsidence rates at individual electric transmission

529 line towers with previous studies. Individual towers in this table are from electrical transmission 530 line 1910, which cuts across Sherman Island from west to east, as shown in Figure 8. The error 531 bars in the UAVSAR subsidence rates indicate only the random component of the uncertainty.

\begin{tabular}{|c|c|c|c|c|c|}
\hline Latitude & Longitude & $\begin{array}{c}\text { Power } \\
\text { pole } \\
\text { number }\end{array}$ & $\begin{array}{c}\text { Subsidence } \\
\text { Rate during } \\
\mathbf{1 9 8 8 - 2 0 0 6} \text { from } \\
\text { Deverel \& } \\
\text { Leighton, 2010 } \\
\text { (cm/yr) }\end{array}$ & $\begin{array}{c}\text { Subsidence } \\
\text { Rate during } \\
\mathbf{1 9 1 0 - 1 9 8 8} \\
\text { from } \\
\text { Rojstaczer } \\
\text { et al., 1991 } \\
\text { (cm/yr) }\end{array}$ & $\begin{array}{c}\text { UAVSAR } \\
\text { Subsidence } \\
\text { Rate } \\
\text { (cm/yr) }\end{array}$ \\
\hline 38.088299 & -121.704203 & 274 & -1.4 & -1.28 & $-1.4 \pm 0.5$ \\
\hline 38.082598 & -121.709647 & 278 & -0.75 & -1.25 & $-0.8 \pm 0.3$ \\
\hline 38.081173 & -121.711535 & 279 & -1.25 & -1.9 & $-0.3 \pm 0.3$ \\
\hline 38.079754 & -121.713427 & 280 & -0.8 & -1.4 & $-0.8 \pm 0.2$ \\
\hline 38.078421 & -121.715182 & 281 & -2.25 & -1.3 & $-0.8 \pm 0.5$ \\
\hline 38.076973 & -121.717149 & 282 & -0.6 & -1.35 & $-0.6 \pm 0.5$ \\
\hline 38.075849 & -121.718661 & 283 & -1.2 & -2.45 & $-0.9 \pm 0.4$ \\
\hline 38.071312 & -121.724722 & 287 & -2.3 & -1.8 & $-1.6 \pm 0.3$ \\
\hline 38.067004 & -121.730468 & 291 & -1.4 & -2.8 & $-1.6 \pm 0.8$ \\
\hline 38.064227 & -121.73419 & 292 & -1.95 & -2.3 & $-1.8 \pm 0.3$ \\
\hline 38.062814 & -121.736092 & 293 & -1.2 & -2.3 & $-1.3 \pm 0.5$ \\
\hline 38.055789 & -121.745479 & 298 & -1.3 & -3 & $-1.2 \pm 0.6$ \\
\hline 38.054372 & -121.74737 & 299 & -0.6 & -3.05 & $-0.6 \pm 0.4$ \\
\hline 38.094372 & -121.702669 & 271 & - & -1.15 & $-1.0 \pm 0.2$ \\
\hline 38.092355 & -121.703191 & 272 & - & -1.28 & $-1.2 \pm 0.3$ \\
\hline 38.090328 & -121.703683 & 273 & - & -2.18 & $-1.8 \pm 0.3$ \\
\hline 38.075559 & -121.719008 & 284 & - & -2.49 & $-1.0 \pm 0.4$ \\
\hline 38.069886 & -121.726614 & 289 & - & -2.6 & $-1.9 \pm 0.4$ \\
\hline 38.061384 & -121.738006 & 294 & - & -2.5 & $-2.0 \pm 0.2$ \\
\hline 38.057192 & -121.743618 & 297 & - & -2.75 & $-0.9 \pm 0.7$ \\
\hline
\end{tabular}

532 
Table 3. Comparison of UAVSAR-derived subsidence rates at individual electric transmission line towers with previous studies. Individual towers in this table are from electrical transmission line 1952, which cuts across Sherman Island from north to south, as shown in Figure 8. The error bars in the UAVSAR subsidence rates indicate only the random component of the uncertainty.

\begin{tabular}{|c|c|c|c|c|}
\hline Latitude & Longitude & $\begin{array}{c}\text { Power pole } \\
\text { number }\end{array}$ & $\begin{array}{c}\text { Subsidence Rate } \\
\text { during 1952-1988 } \\
\text { from Rojstaczer } \\
\text { et al., 1991 } \\
\text { (cm/yr) }\end{array}$ & $\begin{array}{c}\text { Subsidence Rate } \\
\text { (cm/yr) }\end{array}$ \\
\hline 38.064246 & -121.701739 & 10 & -0.14 & $-0.5 \pm 0.2$ \\
\hline 38.06134 & -121.705456 & 11 & -0.78 & $-0.7 \pm 0.2$ \\
\hline 38.060956 & -121.705739 & 12 & -2.78 & $-1.6 \pm 0.3$ \\
\hline 38.067776 & -121.704723 & 13 & -1.52 & $-1.4 \pm 0.5$ \\
\hline 38.063315 & -121.709699 & 14 & -1.94 & $-1.6 \pm 0.2$ \\
\hline 38.06298 & -121.709958 & 15 & -2.22 & $-2.0 \pm 0.3$ \\
\hline 38.070019 & -121.709919 & 16 & -0.97 & $-1.0 \pm 0.2$ \\
\hline 38.064848 & -121.714328 & 18 & -1.38 & $-1.1 \pm 0.6$ \\
\hline 38.072469 & -121.71535 & 19 & -3.47 & $-2.3 \pm 0.5$ \\
\hline 38.068502 & -121.722082 & 20 & -1.94 & $-1.9 \pm 0.2$ \\
\hline 38.068127 & -121.722345 & 21 & -1.25 & $-1.4 \pm 0.2$ \\
\hline 38.074672 & -121.72069 & 22 & -0.28 & $-0.3 \pm 0.5$ \\
\hline
\end{tabular}

544 elevation from September 2010-August 2014 to ground truth our remotely sensed data. The extensometer recorded a subsidence rate of $0.4 \mathrm{~cm} / \mathrm{yr}$ at the location. We calculated the UAVSAR-derived subsidence in a 3-by-3 pixel area centered at the extensometer location for 547 comparison with the extensometer-derived measurement (Figure 13). The average UAVSARmeasured subsidence rate at the extensometer's location is $0.5 \pm 0.1 \mathrm{~cm} / \mathrm{yr}$. Both the UAVSAR 549 and the extensometer estimates represent subsidence resultant primarily from oxidation of 
550 shallow organic soils. We note that the InSAR and extensometer measurements have different

551 references: the UAVSAR measurements are relative to the concrete base of one of the electric

552 transmission line towers in central Sherman Island (Figure 8), and the extensometer records

553 elevation changes relative to a depth of $\sim 20$ feet $(\sim 6.1 \mathrm{~m})$ below land surface (the extensometer

554 legs were driven to refusal into the mineral layer below the peat layer, which is at $\sim 20$ feet $(\sim 6.1$

$555 \mathrm{~m}$ ) below the ground). The difference between the extensometer and InSAR measurements is

$556 \sim 0.1 \mathrm{~cm} / \mathrm{yr}$, which is within our estimated systematic uncertainty $(\sim 0.3 \mathrm{~cm} / \mathrm{yr})$.

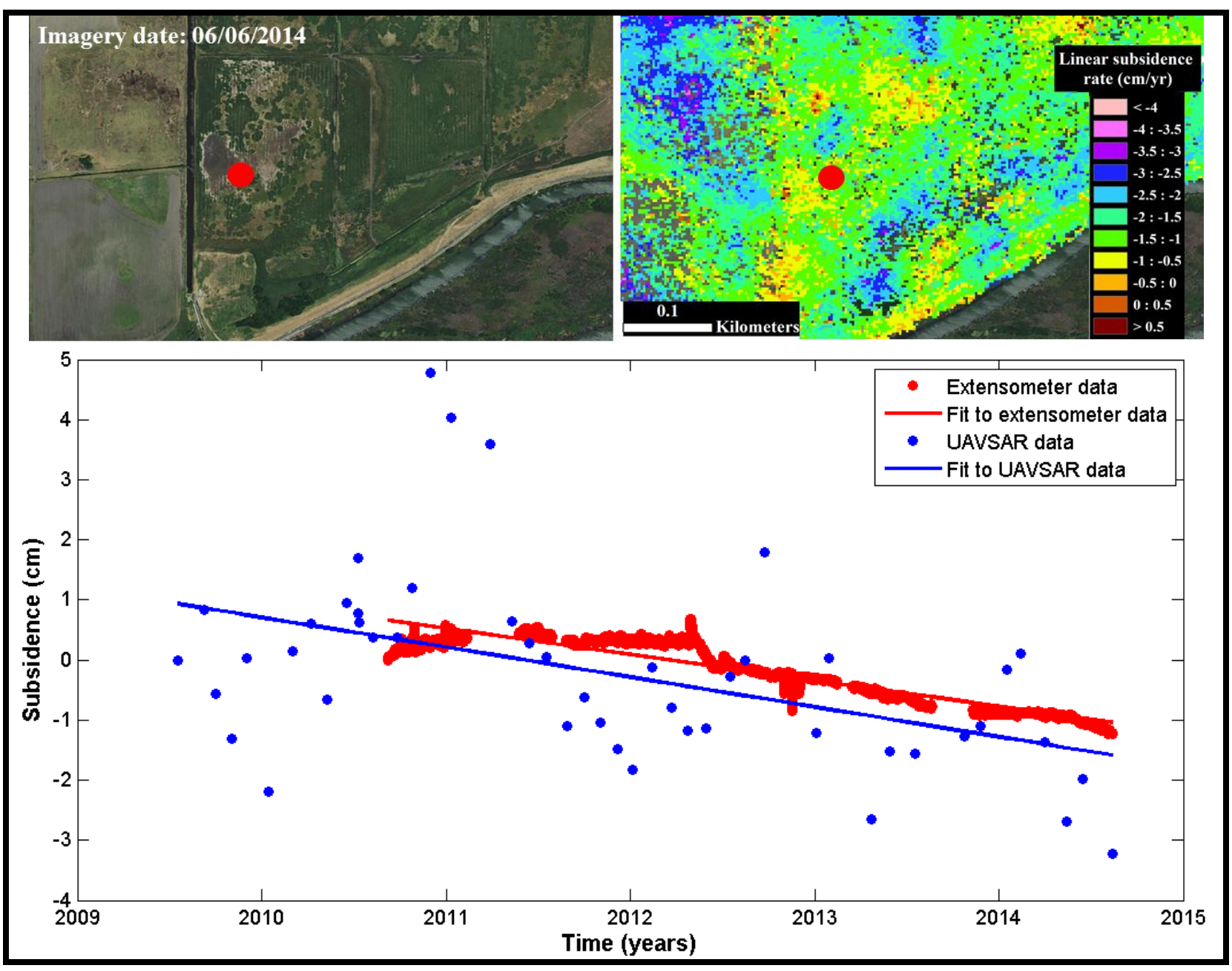


559 Figure 13. Comparison of UAVSAR-measured and extensometer-measured subsidence at 560 location within Sherman Island $\left(38.05^{\circ} \mathrm{N}, 121.71^{\circ} \mathrm{W}\right)$. The extensometer measured a subsidence 561 rate of $0.4 \mathrm{~cm} / \mathrm{yr}$, while the UAVSAR measurements yielded an average rate of $0.5 \pm 0.1 \mathrm{~cm} / \mathrm{yr}$. 562 Location of the extensometer is indicated with a red circle.

563

Cohen et al. (1998) had previously investigated the feasibility of using InSAR for 565 measuring subsidence in the Sacramento-San Joaquin Delta. Rapid decorrelation in the 566 agricultural landscape of the Delta, at the shorter C-band wavelength $(5.66 \mathrm{~cm})$ employed for 567 that study, was found to be a hindrance for calculating accurate subsidence measurements in this 568 region using InSAR. Urban areas located to the west of the Delta were found to maintain 569 reasonable coherence. By applying the Persistent Scatterer (PSInSAR) technique to C-band 570 InSAR data from the ERS-2 satellite, Brooks et al., (2012a) were able to detect individual 571 persistent scatterers within the Delta to be subsiding at a rate of $\sim 3-20 \mathrm{~mm} / \mathrm{yr}$. However, the 572 PSInSAR technique did not allow for calculation of subsidence throughout Sherman Island, 573 except at a few persistent scatterer points located mainly on the northeastern boundary of the 574 island. The longer L-band wavelength $(23.8 \mathrm{~cm})$ UAVSAR data employed for this study, 575 dedicated regular acquisitions and the SBAS data processing technique adapted for a coherence576 challenged area, enabled us to monitor subsidence across Sherman Island at a much finer scale, 577 both spatially and temporally. Table 4 shows a comparison of our average results for the whole 578 island with those of previous studies, both from the extensometer and power pole measurements 579 and with the limited InSAR results available.

580

581 
Table 4. Comparison of UAVSAR-derived results with previous studies of subsidence on

Sherman Island, California.

\begin{tabular}{|c|c|c|c|}
\hline Study & $\begin{array}{l}\text { Time period } \\
\text { covered }\end{array}$ & Method & Average subsidence rates \\
\hline $\begin{array}{c}\text { Rojstaczer et al., 1991; } \\
\text { Rojstaczer and } \\
\text { Deverel, } 1995\end{array}$ & $\begin{array}{l}\text { 1. } 1910-1988 \\
\text { 2. } 1952-1988\end{array}$ & $\begin{array}{l}\text { Power pole } \\
\text { measurements }\end{array}$ & $\begin{array}{l}\text { 1. } 2.3 \mathrm{~cm} / \mathrm{yr} \\
\text { 2. } 1.5 \mathrm{~cm} / \mathrm{yr}\end{array}$ \\
\hline $\begin{array}{c}\text { Deverel and } \\
\text { Rojstaczer, } 1996\end{array}$ & $\begin{array}{l}\text { March 1990- } \\
\text { May } 1992\end{array}$ & Extensometer & $0.46 \mathrm{~cm} / \mathrm{yr}$ \\
\hline $\begin{array}{l}\text { Deverel and Leighton, } \\
2010\end{array}$ & $1988-2006$ & $\begin{array}{l}\text { Power pole } \\
\text { measurements }\end{array}$ & $\begin{array}{c}\text { Average: } 1.3 \mathrm{~cm} / \mathrm{yr} \\
\text { Range: } 0.59-2.24 \mathrm{~cm} / \mathrm{yr}\end{array}$ \\
\hline Brooks et al, 2012a & 1995-2000 & $\begin{array}{l}\text { ERS-2: } \\
\text { PSInSAR } \\
\text { technique }\end{array}$ & $\begin{array}{l}\text { 3-20 mm/yr; very few data } \\
\text { points (persistent } \\
\text { scatterers) available for } \\
\text { Sherman; predominantly } \\
\text { along northeastern } \\
\text { boundary of Sherman }\end{array}$ \\
\hline $\begin{array}{l}\text { Brooks et al., 2012b; } \\
\text { Glennie et al., } 2013\end{array}$ & $\begin{array}{l}16 \text { and } 17 \text { May } \\
2012\end{array}$ & $\begin{array}{l}\text { Balloon } \\
\text { LiDAR }\end{array}$ & $\begin{array}{c}\text { 10's of centimeters of } \\
\text { subsidence by comparison } \\
\text { with 2007-08 CA DWR } \\
\text { LiDAR survey }\end{array}$ \\
\hline $\begin{array}{l}\text { Extensometer results } \\
\text { from this study }\end{array}$ & $\begin{array}{l}\text { September 2010- } \\
\text { August } 2014\end{array}$ & Extensometer & $\begin{array}{c}\text { Subsidence rate: } \\
0.4 \mathrm{~cm} / \mathrm{yr} \text { at one location }\end{array}$ \\
\hline $\begin{array}{l}\text { UAVSAR results from } \\
\text { this study }\end{array}$ & $\begin{array}{l}\text { July 2009- } \\
\text { Aug } 2014\end{array}$ & $\begin{array}{l}\text { UAVSAR: } \\
\text { SBAS } \\
\text { technique }\end{array}$ & $\begin{array}{c}\text { Average subsidence: } \\
5.8 \pm 1.4 \mathrm{~cm} \\
\text { Range of subsidence: } \\
0-25 \mathrm{~cm} \\
\text { Average subsidence rate: } \\
1.3 \pm 0.2 \mathrm{~cm} / \mathrm{yr} \\
\text { Range of subsidence rate: } \\
0-5 \mathrm{~cm} / \mathrm{yr}\end{array}$ \\
\hline
\end{tabular}




\section{Conclusions}

Measuring subsidence in agricultural landscapes in California's Sacramento-San Joaquin Delta with InSAR has been a challenging problem for many years. While the utility of InSAR for monitoring deformation in California's urban and desert areas that maintain phase coherence

591 over long periods of time is well-documented, the use of this technique has been limited in 592 agricultural areas due to rapid decorrelation at the relatively shorter radar wavelengths usually 593 employed for such studies. The novelty of the research described here lies in using longer 594 wavelength (L-band) radar data, acquiring them at relatively short and regular intervals, and 595 using time-series algorithms modified for low-coherence data. This approach minimizes the 596 effects of decorrelation, thus enabling us to calculate deformation and evaluate its spatial and 597 temporal variation across a coherence-challenged area like Sherman Island in the Sacramento598 San Joaquin Delta.

599

The CA DWR LiDAR survey of 2007-08 estimated land elevations as low as 5 meters

601 below sea level in many parts of Sherman Island. UAVSAR-based cumulative subsidence 602 estimates across Sherman Island from 2009-2014 are found to range from 0-25 cm, with the 603 average cumulative subsidence being $\sim 5.8 \pm 1.4 \mathrm{~cm}$. The average subsidence rate across the 604 island is $1.3 \mathrm{~cm} / \mathrm{yr}$ (with $\pm 0.2 \mathrm{~cm} / \mathrm{yr}$ random uncertainty and $\pm 0.3 \mathrm{~cm} / \mathrm{yr}$ systematic 605 uncertainty), and ranges between $0-5 \mathrm{~cm} / \mathrm{yr}$ depending upon location, with substantial 606 heterogeneity at the field scale and, in some areas, over smaller scales. Our subsidence estimates 607 are comparable to measurements from electric transmission line towers, extensometers and 608 LiDAR surveys, carried out in past studies. Our results are also validated by measurements we 
609 took with an extensometer in Sherman Island, during an overlapping time period with the

610 UAVSAR data acquisition. Rojstaczer and Deverel (1995) had found subsidence rates on

611 Sherman Island to vary with soil organic matter content, and we also find soil type to be one of

612 the important factors affecting measured subsidence, with higher organic matter content

613 contributing to an increase in average subsidence rates. Land use (which affects water table

614 depths in the Delta), elevation and timing/location of levee repair also seem to play a significant

615 role in controlling subsidence.

616

617

Sherman Island's location in the western Delta is crucially linked to water supply

618 reliability for the state of California and makes it a prime area of interest for subsidence

619 mitigation studies. This island is a testing ground for evaluating various approaches for

620 subsidence reversal for the Delta. Along with the levee rehabilitation and repair efforts

621 undertaken by the California DWR in Sherman Island over the years, the agency also constructed

622 the Mayberry Farms Subsidence Reversal Project in the island in 2010, focused on the feasibility

623 of creating permanent wetlands for reducing subsidence and sequestering carbon. Other tidal

624 restoration projects are also being examined for their efficiency and sustainability in Sherman

625 Island (Orr et al., 2003; Fischer, 2011; Bates and Lund, 2013; Hatala, 2013; Deverel et al., 2014,

626 2015). The results of this study will directly feed into these investigations of techniques for

627 subsidence reversal in the Delta.

628

629

We plan to extend this analysis to monitor subsidence at a similar scale on the other

630 islands in the Delta and to explore its effect on the levees in the area. Utilizing this dataset and

631 technique for the entire region can greatly help by modernizing and innovating monitoring in the 
632 Delta, through providing more consistently acquired data over the whole Delta, at a high spatial 633 and temporal resolution. Finally, the analysis described in this manuscript is of direct relevance

634 to the upcoming NASA-ISRO Synthetic Aperture Radar (NISAR) mission to be launched in 6352020 (Rosen et al., 2014). The measurements made possible by the frequent (every few weeks) 636 and continuous (for five years) data acquisition for the work described here provide a reference 637 point for the expected results that could be achieved with the NISAR, which will provide global 638 coverage every 12 days, at the same L-band wavelength as the UAVSAR as well as potentially at 639 S-band $(12 \mathrm{~cm})$.

640

641 Acknowledgements

642

643 The authors gratefully acknowledge those who designed, developed and operate the Uninhabited 644 Aerial Vehicle Synthetic Aperture Radar (UAVSAR). We are grateful to the Delta Science 645 Program and the California Sea Grant for awarding the Delta Science Postdoctoral Fellowship to 646 the lead author of this study, which enabled the research described here to be conducted. We 647 thank Mike Gunson and Duane Waliser for their mentorship and financial support during this 648 study. This work was also supported through grants from NASA, Department of Homeland 649 Security, California Department of Water Resources, University of California, Davis, 650 Department of Land, Air and Water Resources and US Department of Agriculture Grant, NIFA \# 651 2011-67003-30371, Sub-award No. 201015552-06. The research described here was carried out 652 in part at the Jet Propulsion Laboratory, California Institute of Technology, under a contract with 653 the National Aeronautics and Space Administration. The UAVSAR data are provided courtesy of 654 NASA/JPL-Caltech. Copyright 2015. All rights reserved. 
657 References

658

659 Agram, P.S., Jolivet, R. and Simons, M. (2012) Generic InSAR Analysis Toolbox (GIAnT) 660 User Guide, http://earthdef.caltech.edu

661

662 Agram, P. S., Jolivet, R., Riel, B., Lin, Y. N., Simons, M., Hetland, E., Doin, M. P. and Lassere, 663 C. (2013). New Radar Interferometric Time Series Analysis Toolbox Released, Eos Trans. 664 American Geophysical Union Meeting, 94, 69.

665

666

Balmer, R. and Hartl, P. (1998) Synthetic aperture radar interferometry. Topical Review. Inverse

667 Problems 14, R1-R54.

668

669 Bates, M.E. and Lund, J.R. (2013) Delta Subsidence Reversal, Levee Failure, and Aquatic 670 Habitat - A Cautionary Tale. San Francisco Estuary and Watershed Science, 11(1).

671

672 Bawden, G.W., W. Thatcher, R.S. Stein, K.W. Hudnut, and G. Peltzer, (2001) Tectonic 673 contraction across Los Angeles after removal of groundwater pumping effects, Nature, 412 674 (6849), 812-815.

675

676 Berardino, P., Fornaro, G., Lanari, R. and Sansosti, E. (2002) A New Algorithm for Surface

677 Deformation Monitoring Based on Small Baseline Differential SAR Interferograms. IEEE 678 Transactions on Geoscience and Remote Sensing, Vol. 40, No. 11.

679 
686

687 688

689

690

691

692 693

694

695

696 697 Central Valley, 136-149.

698

699 California Department of Water Resources, Statewide Planning Branch, Division of Planning 700

701

Biggs, J., Wright, T., Lu, Z. and Parsons, B. (2007) Multi-interferogram method for measuring interseismic deformation: Denali Fault, Alaska. Geophysical Journal International, Volume 170, Issue 3, pages $1165-1179$.

Broadbent F. (1960) Factors influencing the decomposition of organic soils of the California delta. Hilgardia 29(13):587-612. DOI:10.3733/hilg.v29n13p587

Brooks, B. A., Bawden, G., Manjunath, D., Werner, C., Knowles, N. and Foster, J. (2012a). Contemporaneous Subsidence and Levee Overtopping Potential, Sacramento-San Joaquin Delta, California. San Francisco Estuary and Watershed Science, 10(1).

Brooks, B.A., Glennie, C.L., Ericksen, T.L., Foster, J.H., Hudnut, K.W., Hauser, D. and Avery, J. (2012b) 4-D monitoring of levee stability from Balloon and Airborne LIDAR data sets, Sherman Island, Sacramento Delta. 2012 AGU Fall Meeting, abstract G23A-0883.

Burton, C. and Cutter, S.L. (2008) "Levee Failures and Social Vulnerability in the SacramentoSan Joaquin Delta Area, California.” Nat. Hazards Rev. 9, SPECIAL ISSUE: Flooding in the and Local Assistance (2007a) Land Use Survey. 
702 California Department of Water Resources, Delta-Suisun Marsh office (2007b). Sacramento-San 703 Joaquin Delta LiDAR Acquisition.

704

705 California Department of Water Resources (2009) Delta Risk Management Strategy (DRMS)

706 Risk Analysis Report. Executive Summary Phase 1. (2009). Prepared by the California

707 Department of Water Resources from documents developed by URS Corporation/Jack R.

708 Benjamin \& Associates, Inc., 32 p. Available from:

709 http://www.water.ca.gov/floodsafe/fessro/levees/drms/docs/drms_execsum_ph1_final_low.pdf

710

711 Cavalié, O., Doin, M.-P., Lasserre, C. and Briole, P. (2007) Ground motion measurement in the

712 Lake Mead area, Nevada, by differential synthetic aperture radar interferometry time series

713 analysis: Probing the lithosphere rheological structure. (2007) Journal of Geophysical Research:

714 Solid Earth, Volume 112, Issue B3, doi: 10.1029/2006JB004344.

715

716 Cavalié, O., Lasserre, C., Doin, M.-P., Peltzer, G., Sun, J., Xu, X. and Shen, Z.-K. (2008).

717 Measurement of interseismic strain across the Haiyuan fault (Gansu, China), by InSAR. Earth

718 and Planetary Science Letters, Volume 275, Issues 3-4, Pages 246-257.

719

720 Chen, C. W. and Zebker, H. A. (2001). Two-dimensional phase unwrapping with use of 721 statistical models for cost functions in nonlinear optimization, Journal of the Optical Society of 722 America A, vol. 18, pp. 338-351.

723 
724 Cohen, D.A., Deverel, S.J. and Johnson, L.A. (1998) Feasibility study of differential SAR 725 interferometry for subsidence monitoring in the Sacramento-San Joaquin Delta. 1998 IEEE 726 International Geoscience and Remote Sensing Symposium, IGARSS, Volume 3, pp. 1629-1631.

727

728 Cosby, S.W. (1941) Soil survey of the Sacramento-San Joaquin Delta area, California. U.S. 729 Bureau of Plant Industry, Soil Surveys, Series 1935, No. 21, 48 pp.

730

731 Delta Science Plan (2013) One Delta, One Science.

732 http://deltacouncil.ca.gov/sites/default/files/documents/files/Delta-Science-Plan-12-30-2013.pdf

733

734 Deverel, S.J. and Rojstaczer, S.A. (1996) Subsidence of agricultural lands in the Sacramento735 San Joaquin. Water Resources Research, vol. 32, no. 8, pp. 2359-2367.

736

737 Deverel, S. J. and Leighton, D. A. (2010) Historic, Recent, and Future Subsidence, Sacramento738 San Joaquin Delta, California, USA. San Francisco Estuary and Watershed Science, 8(2). 739

Deverel, S. J., Ingrum, T., Lucero, C. and Drexler, J. Z. (2014) Impounded Marshes on Subsided 741 Islands: Simulated Vertical Accretion, Processes, and Effects, Sacramento-San Joaquin Delta, 742 CA USA. San Francisco Estuary and Watershed Science, 12(2).

743

744 Deverel, S.J., Ingrum, T. and Leighton, D. (2015) Present-day Oxidative Subsidence of Organic 745 Soils and Mitigation in the Sacramento-San Joaquin Delta, California, USA. Hydrogeology 746 Journal (submitted). 
748 Doin, M. P., Lasserre, C., Peltzer, G., Cavalie, O. and Doubre, C. (2009) Corrections of stratified 749 tropospheric delays in SAR interferometry: Validation with global atmospheric models. J. App.

750 Geophys., Volume 69, Issue 1, Pages 35-50, doi: f10.1016/j.jappgeo.2009.03.010g.

751

752 Efron, B. and Stein, C. (1981). "The Jackknife Estimate of Variance". The Annals of Statistics, 9 753 (3): 586-596. doi:10.1214/aos/1176345462.

754

755 European Space Agency (ESA) (2007) InSAR Principles: Guidelines for SAR Interferometry 756 Processing and Interpretation Training Manual (TM-19). Ed. Karen Fletcher. ESA Publications. 757

758 Fisher, R., Miyamoto, C., Nguyen, K. and Whipple, R. (2011) Sustaining Sherman Island: A 759 Water Management and Agricultural Diversification System. Berkeley Scientific Journal, 15(2). 760

761 Gabriel, A. K., Goldstein, R. M. and Zebker, H. A. (1989) Mapping small elevation changes over 762 large areas: Differential radar interferometry, J. Geophys. Res., 94(B7), 9183-9191, 763 doi:10.1029/JB094iB07p09183.

764

765 Glennie, C., Brooks, B., Ericksen, T., Hauser, D., Hudnut, K., Foster, J. and Avery, J. (2013) 766 Compact Multipurpose Mobile Laser Scanning System — Initial Tests and Results. Remote 767 Sens., 5, 521-538. 
769

770

771

772

773

774

775

776

777

778

779

780 781

782

783

784

785

786

787

788

789

790

791

Hanssen, R.F. (2001) Radar Interferometry-Data Interpretation and Error Analysis. Norwell, MA, USA: Kluwer.

Hatala, J. (2013) Spatiotemporal dynamics of carbon dioxide and methane fluxes from agricultural and restored wetlands in the California Delta. PhD Thesis. UC Berkeley Electronic Theses and Dissertations. Available from: https://escholarship.org/uc/item/8857w19f

Hensley, S.; Wheeler, K.; Sadowy, G.; Jones, C.; Shaffer, S.; Zebker, H.; Miller, T.; Heavey, B.; Chuang, E.; Chao, R.; Vines, K.; Nishimoto, K.; Prater, J.; Carrico, B.; Chamberlain, N.; Shimada, J.; Simard, M.; Chapman, B.; Muellerschoen, R.; Le, C.; Michel, T.; Hamilton, G.; Robison, D.; Neumann, G.; Meyer, R.; Smith, P.; Granger, J.; Rosen, P.; Flower, D.; Smith, R. (2008) "The UAVSAR instrument: Description and first results," IEEE Radar Conference, pp.16.

Hensley, S., Zebker, H.A., Jones, C., E., Michel, T., Muellerschoen, R. and B. Chapman, B. (2009) First deformation results using the NASA/JPL UAVSAR instrument, Proceedings of the 2nd Asian-Pacific Conference on Synthetic Aperture Radar, 26-30 Oct., 2009 Xi'an, Shanxi, pp. 1051-1055, 2009.

Jolivet, R., Grandin, R., Lasserre, C., Doin, M. P. and Peltzer, G. (2011) Systematic insar tropospheric phase delay corrections from global meteorological reanalysis data. Geophys. Res. Lett., 38(L17311). doi: 10.1029/2011GL048757. 
792 Jolivet, R. and Agram, P.S. (2012) Python-based atmospheric phase screen mitigation using 793 atmospheric re-analysis, URL http://pyaps.googlecode.com.

795 Jolivet, R., C. Lasserre, M.-P. Doin, S. Guillaso, G. Peltzer, R. Dailu, and J. Sun. (2012) Shallow 796 creep on the Haiyuan Fault (Gansu, China) revealed by SAR Interferometry. Journal of 797 Geophysical Research, Vol. 117, B06401, doi:10.1029/2011JB008732, 2012.

799 Jones, C., G. Bawden, S. Deverel, J. Dudas and S. Hensley (2011) "Characterizing land surface 800 change and levee stability in the Sacramento-San Joaquin delta using UAVSAR radar imagery", 801 IEEE International Geoscience and Remote Sensing Symposium, IGARSS, pp. 1638-1641.

802

803 Jones, C., G. Bawden, S. Deverel, J. Dudas, S. Hensley and S.-H. Yun (2012) "Study of 804 movement and seepage along levees using DINSAR and the airborne UAVSAR instrument", 805 SAR Image Analysis, Modeling, and Techniques XII. Proceedings of the SPIE, Volume 8536, 806 article id. 85360E, 8 pp. (2012).

807

808 Jones, C. E., Dudas, J., Bawden, G. W. (2016) “Application of remote sensing to assessment of 809 water conveyance infrastructure integrity," In R. L. Anderson and H. Ferriz (Eds.), Applied 810 Geology in California, Special Publication 26. Association of Environmental and Engineering 811 Geologists, Star Publishing Company, in press.

812

813 Lin, Y.N., Mark Simons, Eric A. Hetland, Pablo Muse and Christopher DiCaprio (2010) A 814 multiscale approach to estimating topographically correlated propagation delays in radar 
815 interferograms. Geochemistry, Geophysics, Geosystems, Volume 11, Issue 9, doi:

$81610.1029 / 2010$ GC003228.

817

818 Lund, J.R. et al. (2010) Comparing futures for the Sacramento-San Joaquin delta. Freshwater 819 Ecology Series. Vol. 3. University of California Press.

820

821 Mesinger, F., DiMego, G., Kalnay, E., Mitchell, K., Shafran, P.C., Ebisuzaki, W., Jović, D.,

822 Woollen, J., Rogers, E., Berbery, E.H., Ek, M.B., Fan, Y., Grumbine, R., Higgins, W., Li, H., 823 Lin, Y., Manikin, G., Parrish, D. and Shi, W. (2006) North American Regional Reanalysis 824 Bulletin of the American Meteorological Society, Volume 87, Issue 3, pp. 343-360, doi: 825 http://dx.doi.org/10.1175/BAMS-87-3-343

826

827 Mount, J. and Twiss, R. (2005) "Subsidence, sea level rise, and seismicity in the Sacramento-San 828 Joaquin Delta," San Francisco Estuary and Watershed Science, 3(1).

829

830 National Resources Conservation Service Soils, United States Department of Agriculture (1985)

831 Soil Survey of Sacramento County, California.

832

833 Orr, M., Crooks, S. and Williams, P.B. (2003) Will Restored Tidal Marshes Be Sustainable? San 834 Francisco Estuary and Watershed Science, 1(1).

835

836 Prokopovich, N. P. (1985) Subsidence of peat in California and Florida, Bull. Assoc. Eng. Geol., $837 \quad 22,395-420$. 
839 Reeves, J.A., Knight, R. and Zebker, H.A. (2014) An Analysis of the Uncertainty in InSAR

840 Deformation Measurements for Groundwater Applications in Agricultural Areas. IEEE Journal 841 of selected topics in applied earth observations and remote sensing, Vol. 7, No. 7.

842

843 Richards, M.A. (2007) A Beginner's Guide to Interferometric SAR Concepts and Signal 844 Processing. IEEE Aerospace and Electronic Systems Magazine, Vol. 22, No. 9, pp. 5-29.

845

846 Rojstaczer, S.A., Hamon, R.E., Deverel, S.J. and Massey, C.A. (1991) Evaluation of selected 847 data to assess the causes of subsidence in the Sacramento-San Joaquin Delta, California. U.S. 848 Geological Survey Open File Report 91-193.

849

850 Rojstaczer, S.A. and Deverel, S.J. (1993) Time dependence in atmospheric carbon inputs from 851 drainage of organic soils. Geophysical Research Letters 20:1383-1386.

852

853 Rojstaczer, S.A and Deverel, S.J. (1995) Land subsidence in drained histosols and highly organic 854 mineral soils of California. Soil Science Society of America Journal 59:1162-1167.

855

856 Rosen, P.A., Hensley, S., Joughin, I.R., Fuk K.Li., Madsen, S.N., Rodriguez, E. and Goldstein, 857 R. M. (2000). Synthetic Aperture Radar Interferometry. Proceedings of the IEEE, Vol 88, Issue 858 3, pg. 333-382, doi: 10.1109/5.838084 
860 Rosen, P. A.; Kim, Yunjin; Hensley, Scott; Shaffer, Scott; Veilleux, Louise; Hoffman, James;

861 Chuang, Chung-Lun; Chakraborty, Manab; Sagi, V.Raju; Satish, R.; Putrevu, Deepak; Bhan,

862 Rakesh. An L- and S-band SAR Mission Concept for Earth Science and Applications. (2014)

863 EUSAR 2014, Proceedings of 10th European Conference on Synthetic Aperture Radar, pp 1-4.

864

865 Service, R. F. (2007) Delta blues, California style. Science, 317(5837), 442-445.

866

867 Simley, J.D. and Carswell Jr., W.J. (2009) The National Map-Hydrography: U.S. Geological

868 Survey Fact Sheet 2009-3054, 4 p.

869

870 Stephens, J.C., Allen, L.H. and Chen E. (1984) Organic soil subsidence. In: Holzer TL, editor.

871 Man-induced land subsidence. Reviews in Engineering Geology, Vol. VI. Boulder (CO):

872 Geological Society of America.

873

874 Suddeth, R.J., Mount, J. and Lund, J.R. (2010) Levee Decisions and Sustainability for the 875 Sacramento-San Joaquin Delta. San Francisco Estuary and Watershed Science, 8(2).

876

877 Torres RA, et al. (2000). Seismic vulnerability of the Sacramento-San Joaquin Delta levees. 878 Report of levees and channels technical team, seismic vulnerability sub-team to CALFED Bay879 Delta Program. 30 p.

880 
881 United States Environmental Protection Agency [USEPA]. (2011) Advanced Notice of Proposed

882 Rulemaking for Water Quality Challenges in the San Francisco Bay/ Sacramento-San Joaquin 883 Delta Estuary.

884

885 URS Corporation and J.R. Benjamin \& Assoc. (2009). Risk Report Section 2. Sacramento/San 886 Joaquin Delta and Suisun Marsh. In: Delta risk management strategy (DRMS) phase 1 final risk 887 analysis report. Prepared for the California Department of Water Resources. 20 p. Available 888 from:

889 http://www.water.ca.gov/floodsafe/fessro/levees/drms/docs/Risk_Report_Section_2_Final.pdf

890

891 Weir, W. W. (1950) Subsidence of peat lands of the San Joaquin-Sacramento Delta, California, 892 Hilgardia, 20, 37-56.

893

894 Zebker, H. A. and Goldstein, R. M. (1986) Topographic mapping from interferometric synthetic 895 aperture radar observations, J. Geophys. Res., 91(B5), 4993-4999, 896 doi:10.1029/JB091iB05p04993.

897

898 List of figure captions

899

900 Figure 1. The Sacramento and San Joaquin Rivers join east of the San Francisco Bay in northern 901 California, forming the Delta. The westernmost island in the Delta, Sherman Island, is the focus 902 of this study (outlined in red). Cities forming the boundaries of the Delta are cited in the text and 903 their locations are depicted in this figure. 
905 Figure 2. Land elevation across the Delta derived from LiDAR topographic survey conducted by 906 the California Department of Water Resources (CA DWR) in 2007-08.

907

908

Figure 3. [A] LiDAR elevations across Sherman Island from the topographic survey conducted

909 by CA DWR in 2007; UTM Zone 10, NAD 83, vertical datum NAVD88 (CA DWR, 2007b), [B]

910 Soil type classification (NRCSS, 1985) and [C] land use classification (CA DWR, 2007a) across

911 Sherman Island. It is important to point out that land use classification varies from year to year 912 and thus this survey from 2007 might not accurately depict the current land use status in the

913 island. Similarly, the soil type map is only intended to provide an island-wide distribution of 914 common soil types and should be used with caution for understanding the effect of soil organic 915 matter content on subsidence.

917 Figure 4. Two UAVSAR lines cover the Sherman Island in the Delta from different look 918 directions. The inset shows the NASA Gulfstream G-III aircraft that carries the UAVSAR. 919

Figure 5. The basic principle of InSAR is demonstrated in this figure. When the radar instrument 921 is flown over a patch of ground the first time (first pass), it transmits microwave pulses towards 922 the surface of the Earth and receives the reflected echo of the radar signal. The incident and 923 reflected signal can be compared in terms of change in amplitude and phase. During the second 924 pass, the radar instrument flies again over the same region to measure new reflection and change 925 of range (distance between instrument and land surface) along line-of-sight direction through the 926 relative change in the phase of the returned signal. (Image credit: Paul A. Rosen) 
928 Figure 6. Overview of processing methodology

930 Figure 7. Pairs of acquisitions used for forming interferograms for both lines (15502 and 23518)

931 are shown in this figure. 47 data acquisitions taken by the UAVSAR were utilized to generate

932168 interferograms for line 15502, and 50 acquisitions were used to generate 198 interferograms

933 for line 23518. Each acquisition is used for forming a minimum of five interferograms.

935 Figure 8. [A] Location of the reference point used for this study in Google Earth® optical

936 imagery. The reference region is at the base of one of the electric transmission line towers

$937\left(\sim 38.07^{\circ} \mathrm{N}, 121.71^{\circ} \mathrm{W}\right)$ located within Sherman Island. The locations of electrical transmission

938 power lines used for comparison with previous studies are also indicated in panel A. The

939 transmission line built in 1910 cuts across Sherman Island from west to east, and the 940 transmission line built in 1952 cuts across from north to south. Location of the extensometer that

941 is used for providing ground-truth for UAVSAR measurements is also shown. Close-up views of 942 the reference region location at increasing resolutions are shown in the bottom left [B] and 943 bottom right [C] panels.

944

945 Figure 9. Example of an interferogram with magnitude (upper left) and phase (upper right) 946 information, coherence (lower left) and water mask (lower right) for line 15502. Each of the sub947 figures is shown in radar (range/azimuth) coordinates. Line ID: 15502, Dates of acquisition: 948 2010-09-25 and 2010-10-25, Temporal baseline: 31 days. 
950 Figure 10. [A] Subsidence rates on Sherman Island derived from a weighted linear fit to the 951 cumulative subsidence vs. time, from July 18, 2009 to August 14, 2014. [B] Uncertainty in 952 subsidence rate $(\mathrm{cm} / \mathrm{yr})$. [C] Standard deviation in the subsidence rates calculated from the two 953 UAVSAR lines, 15502 and 23518. Black pixels in this image indicate the ones for which 954 subsidence was calculated from one line only.

956 Figure 11. [A] Variation of average subsidence rates with soil type (organic matter content) 957 across the whole island is shown. Greater organic matter content in soils is generally associated 958 with higher average subsidence rates. [B] Higher subsidence rates are observed for lower 959 elevations. [C] Correlation is observed between soil organic content and elevation, with higher 960 organic content soils being generally associated with lower elevations (exceptions include 961 Sailboat, Sailboat Variant and Egbert soil types). Land elevations reported in Figs. 11B and 11C 962 have been measured with respect to vertical datum NAVD88 (CA DWR, 2007b).

964 Figure 12. Examples of small-scale subsidence features observed across Sherman Island with 965 UAVSAR are shown in this figure. The top panel shows locations of these features outlined in 966 black rectangles. (a) The yellow star shows an area adjacent to the levee in southwestern 967 Sherman Island that experienced $\sim 25 \mathrm{~cm}$ of subsidence over the five years of our study. Optical 968 imagery of the feature shows a scour pond and a dredge disposal site. The red star shows 969 subsidence vs. time for a nearby point that does not exhibit rapid subsidence, but instead slow 970 subsidence with much larger seasonal oscillations in land elevation. (b) Subsidence feature in 971 central Sherman Island that shows a mix of subsidence and seasonal oscillation in its elevation 972 trend. (c) Subsidence feature in northeastern Sherman Island that is partially correlated with 
973 variation of soil type. (d) The 'tail' section in northeastern Sherman Island shows subsidence

974 variation that generally follows the variation of topography and soil type.

975

976 Figure 13. Comparison of UAVSAR-measured and extensometer-measured subsidence at 977 location within Sherman Island $\left(38.05^{\circ} \mathrm{N}, 121.71^{\circ} \mathrm{W}\right)$. The extensometer measured a subsidence 978 rate of $0.4 \mathrm{~cm} / \mathrm{yr}$, while the UAVSAR measurements yielded an average rate of $0.5 \pm 0.1 \mathrm{~cm} / \mathrm{yr}$. 979 Location of the extensometer is indicated with a red circle.

980

981 List of table captions

982

983 Table 1. Inventory of UAVSAR acquisitions used in this study.

984

985 Table 2. Comparison of UAVSAR-derived subsidence rates at individual electric transmission 986 line towers with previous studies. Individual towers in this table are from electrical transmission 987 line 1910, which cuts across Sherman Island from west to east, as shown in Figure 8. The error 988 bars in the UAVSAR subsidence rates indicate only the random component of the uncertainty. 989

990 Table 3. Comparison of UAVSAR-derived subsidence rates at individual electric transmission 991 line towers with previous studies. Individual towers in this table are from electrical transmission 992 line 1952, which cuts across Sherman Island from north to south, as shown in Figure 8. The error 993 bars in the UAVSAR subsidence rates indicate only the random component of the uncertainty. 994 
995 Table 4. Comparison of UAVSAR-derived results with previous studies of subsidence on 996 Sherman Island, California.

997 